\title{
Availability, use and quality of care for medical abortion services in private facilities in Kenya
}

Wilson Liambila

Population Council

Francis Obare

Population Council

Edward Ikiugu

Vitalis Akora

Jesse Njunguru

See next page for additional authors

Follow this and additional works at: https://knowledgecommons.popcouncil.org/departments_sbsr-rh

Part of the Demography, Population, and Ecology Commons, Family, Life Course, and Society Commons, International Public Health Commons, Maternal and Child Health Commons, Obstetrics and Gynecology Commons, and the Women's Health Commons How does access to this work benefit you? Let us know!

\section{Recommended Citation}

Liambila, Wilson, Francis Obare, Edward Ikiugu, Vitalis Akora, Jesse Njunguru, Michael Njuma, Kate Reiss, and Harriet Birungi. 2015. "Availability, use and quality of care for medical abortion services in private facilities in Kenya," STEP UP Report. Nairobi: Population Council and Marie Stopes International. 


\section{Authors}

Wilson Liambila, Francis Obare, Edward Ikiugu, Vitalis Akora, Jesse Njunguru, Michael Njuma, Kate Reiss, and Harriet Birungi 
Wilson Liambila ${ }^{1}$

Francis Obare ${ }^{1}$ Edward Ikiugu²

Vitalis Akora ${ }^{2}$ Jesee Njunguru² Michael Njuma² Kate Reiss ${ }^{3}$ Harriet Birungi1 


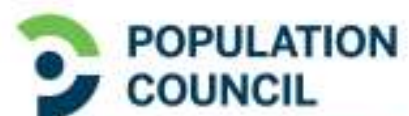 \\ Ideas. Evidence. Impact.}

The Population Council confronts critical health and development issues-from stopping the spread of HIV to improving reproductive health and ensuring that young people lead full and productive lives. Through biomedical, social science, and public health research in 50 countries, we work with our partners to deliver solutions that lead to more effective policies, programs, and technologies that improve lives around the world. Established in 1952 and headquartered in New York, the Council is a nongovernmental, non-profit organization governed by an international board of trustees.

Population Council

General Accident House

Ralph Bunche Road

P.O. Box 17643

Nairobi, Kenya 00500

popcouncil.org

Suggested citation: Liambila, Wilson, Francis Obare, Edward Ikiugu, Vitalis Akora, Jesee Njunguru, Michael Njuma, Kate Reiss, and Harriet Birungi. 2015. "Availability, use and quality of care for medical abortion services in private facilities in Kenya." Nairobi: Population Council and Marie Stopes International. 


\section{Table of Contents}

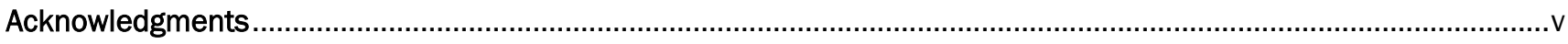

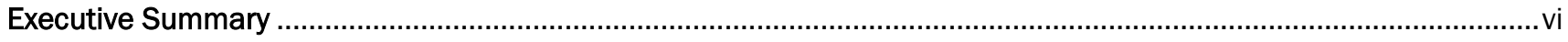

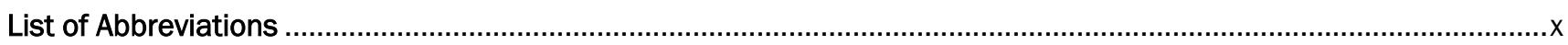

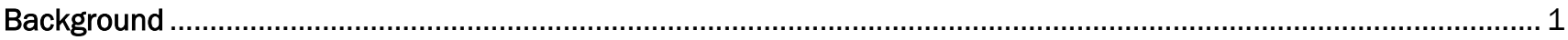

Abortion Environment in Kenya: Perspectives of Key Informants ............................................................. 3

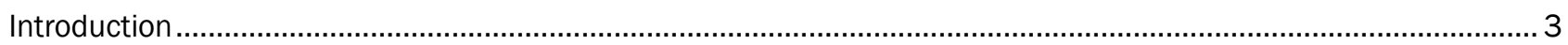

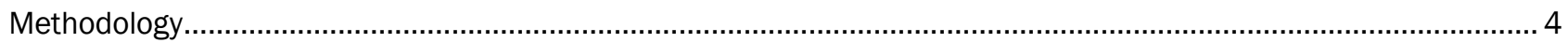

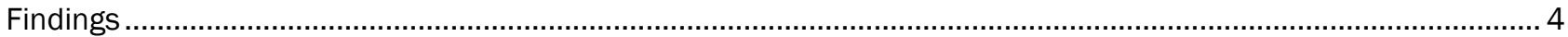

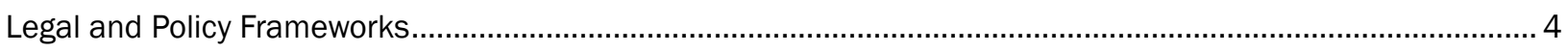

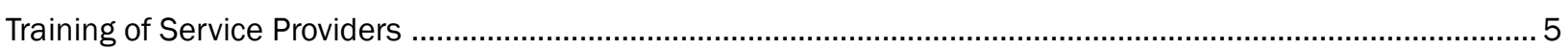

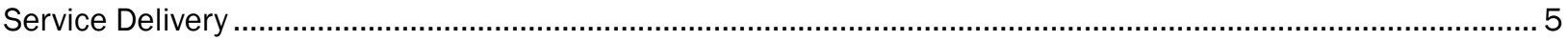

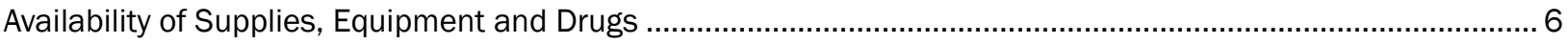

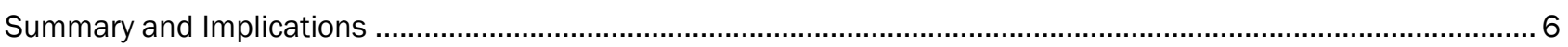

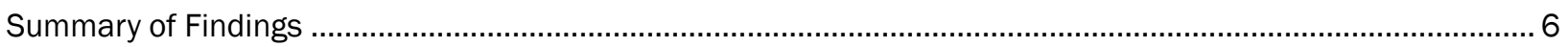

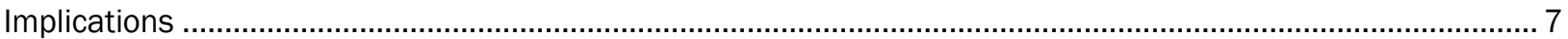

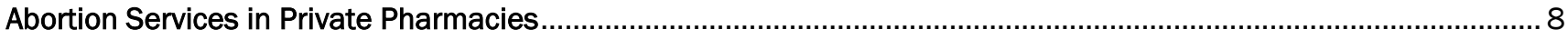

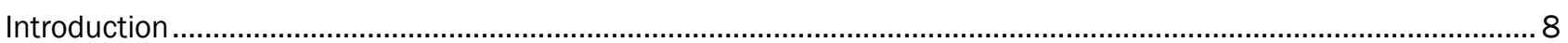

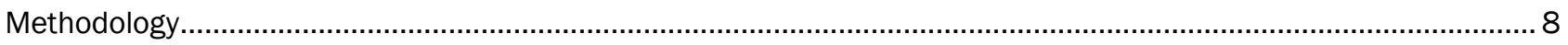

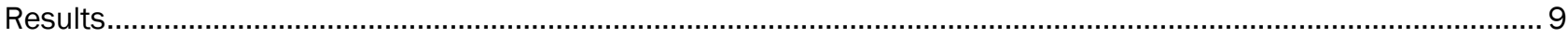

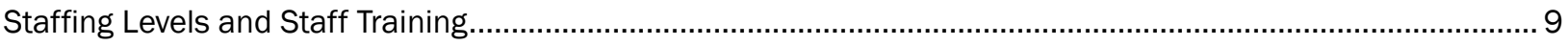

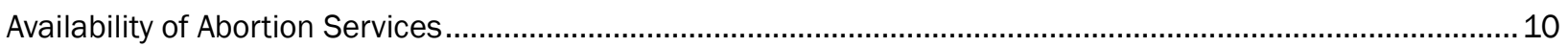

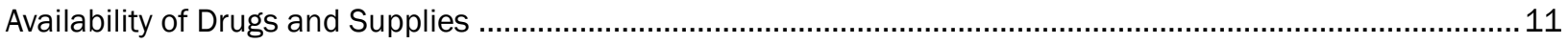

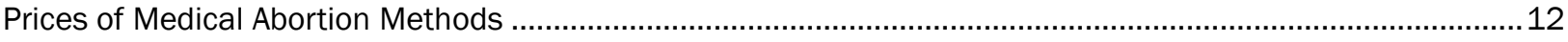

Knowledge and Attitudes of Pharmacy Workers......................................................................................... 12

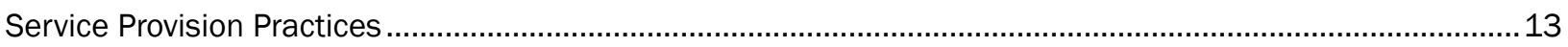

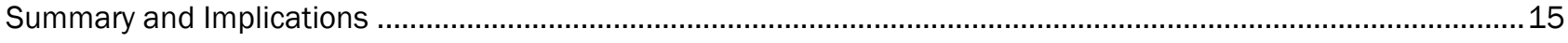

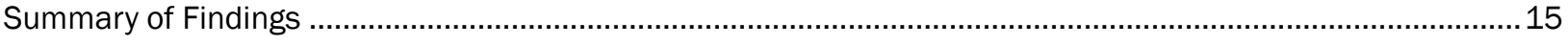

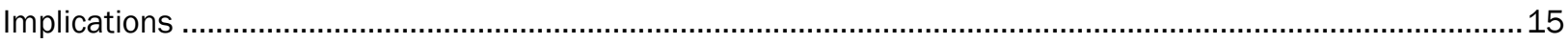

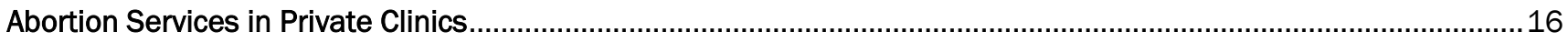

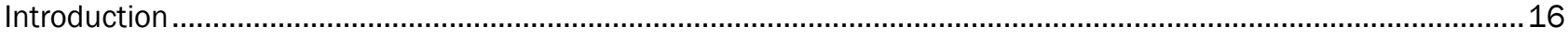

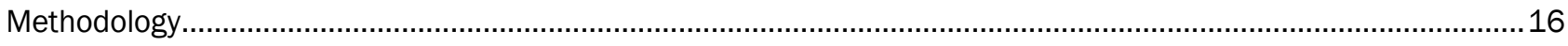

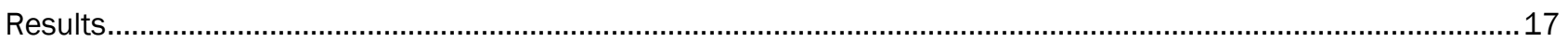

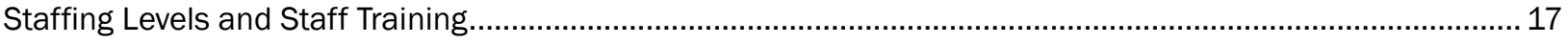

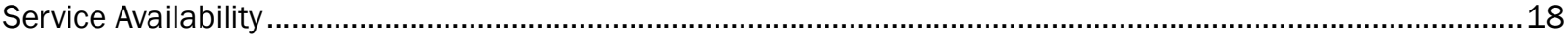

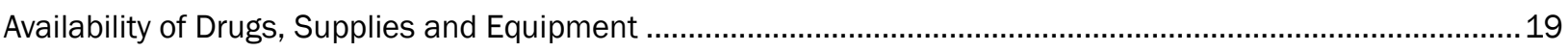

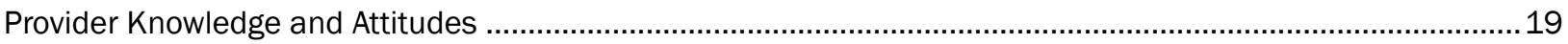




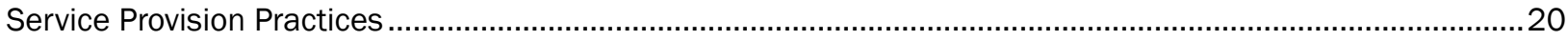

Characteristics of Clients Seeking Abortion Services.............................................................................2

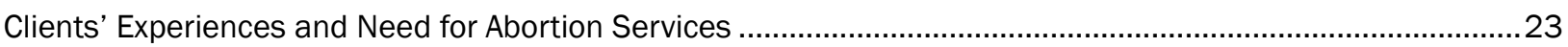

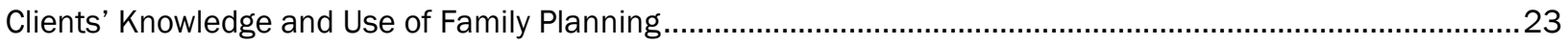

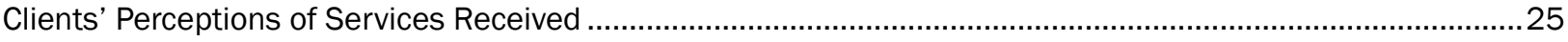

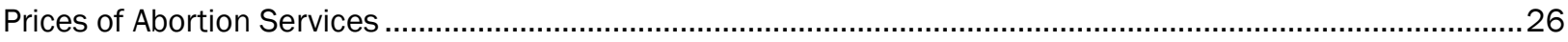

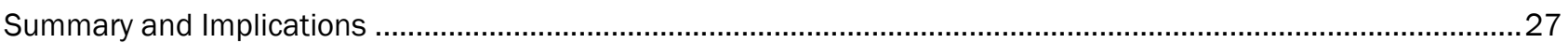

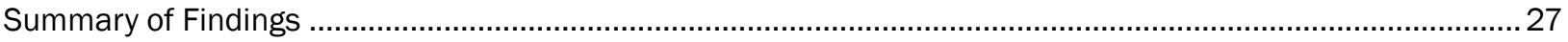

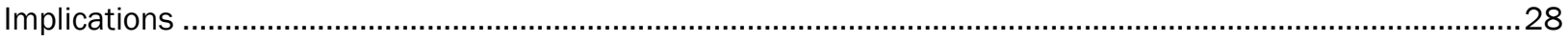

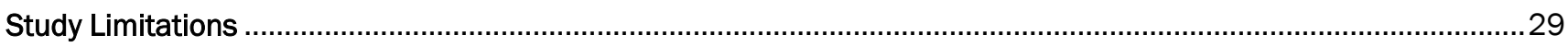

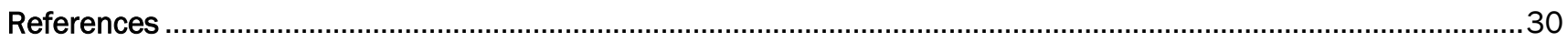

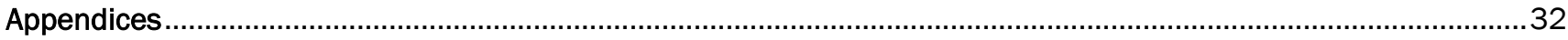




\section{Acknowledgments}

The study that provided the data for this report was funded by UKaid from the Department for International Development (DFID) through STEP UP (Strengthening Evidence for Programming on Unintended Pregnancy) Research Programme Consortium. The study was implemented by the Population Council in collaboration with Marie Stopes Kenya (MSK) and the Reproductive Health Network (RHN). Dr. Washington Onyango-Ouma of the Institute of Anthropology, Gender and African Studies (IAGAS), University of Nairobi, conducted the key informant interviews.

The initial concept paper for the study was developed by Lisbeth Vogensen as part of her internship program with the Population Council, Nairobi. Data collection for the clinic component of the study was undertaken by Vivian Nyansarora Mariita, Elizabeth Akinyi Omondi, Linda Mutoro Sifuna, Linda Agina, Humphrey Masinde, Jane Musia, Beryl Ogutu, Salome Njambi, Fridah Mosero Mogoi, Eunice Adego Asala, Purity Mutono Ndivo, and Judith Mbeka. Data for the pharmacy component were collected by Lucyline Riungu, Brettah Mbula, Vivian Nyansarora Mariita, Florence Anyango, Valentine Jelimo, Linda Kekoi Litu, Loice Akoth Owino, Sheila Bayley, Valery Adhiambo, Christine Amunga, Hellen Murugi, Purity Mbaabu, Maureen Yienya, Harriet Ong'ete, Beryl Ogutu, Judy Njoroge, Priston Ogoti, and Grace Rogena. We further acknowledge the valuable cooperation received from the key informants, the in-charges of the facilities, pharmacy workers, and clients.

Joyce Ombeva of the Population Council provided invaluable administrative support for the project, while Brian Mdawida and Arnold Assava oversaw the designing of the databases and data entry.

Ethical and research clearance for the study was granted by the Institutional Review Boards of the Population Council and Marie Stopes International, the Ethics Review Committee of the Kenya Medical Research Institute (KEMRI), and the National Council for Science and Technology (NCST). 


\section{Executive Summary}

\section{BACKGROUND}

In Kenya, the maternal mortality ratio remains high at 488 deaths per 100,000 live births with 35 per cent of these deaths arising from unsafe abortion. Public debate on abortion and on proposals to liberalize the abortion law has been on-going for several years in the country. With the passing of a new Constitution in 2010, there was renewed interest in the right to health and the need to reduce the high levels of maternal morbidity and mortality arising from unsafe abortion in the country. In 2012, for instance, the Government issued Standards and Guidelines for Reducing Morbidity and Maternal from Unsafe Abortion that emphasized professional nonjudgmental counseling and provision of safe options in cases of unplanned, risky or unwanted pregnancies in line with the Constitution. The Constitution, on the other hand, stipulates that abortion is permissible if in the opinion of a trained health professional, there is need for emergency treatment, or the life or health of the mother is in danger or as determined by any other law. Apart from the legal and policy discourses, medical abortion using a combination treatment of Mifepristone and Misoprostol has been classified by WHO as a safe and effective method to stop a pregnancy up to 9 completed weeks since the last menstrual period i.e. during the first trimester. The two drugs are registered in Kenya for various indications, including treatment of incomplete abortion and miscarriage, treatment and prevention of post-partum haemorrhage (PPH), treatment of intrauterine foetal death, cervical ripening, and as a uterotonic drug to induce or increase uterine contractions. In spite of the developments, there is limited understanding of the extent to which the changes have influenced the provision of medical abortion information and services in the country, the acceptability of the practice among providers and clients, and the content of care offered.

\section{OBJECTIVES}

The overall goal of the study was to generate evidence on the availability, use and quality of care for medical abortion services in private facilities (pharmacies and clinics) in Kenya. The specific objectives of the study were to: (1) understand the contextual and programmatic factors that influence or are likely to influence the provision of medical abortion services in Kenya; (2) explore the perspectives (positive and negative) of various stakeholders about abortion generally and the provision of medical abortion services specifically; (3) assess the availability of Mifepristone and Misoprostol or other abortifacient as well as the skills and practices of private providers; (4) examine the knowledge and attitudes of private providers regarding Mifepristone and Misoprostol or other abortifacients; (5) determine the characteristics, choices and perceptions of clients seeking abortion services from private clinics; and (6) explore the information and services given to clients seeking medical abortion services from private pharmacies and clinics. Private facilities were targeted because access to information and services on medical abortion in Kenya is mainly through private practitioners while public health facilities mostly provide post-abortion care services. Private clinics are operated by the cadres of providers that fall within the legal definition of a health professional including doctors, clinical officers, nurses and midwives while registered pharmacists and enrolled pharmaceutical technologists are the only cadres of health personnel qualified to dispense medicines and operate private pharmacies in the country.

\section{METHODS}

This was a cross-sectional study that was conducted between April and June 2013 in Nairobi, Kisumu and Mombasa counties. The study involved: (1) key informant interviews with 19 senior managers from national and locally-based international institutions representing policy, program, research and donor interests in reproductive health in general and medical abortion in particular; (2) structured interviews with 235 pharmacy workers in 235 private pharmacies; (3) 401 simulated client visits to 142 private pharmacies whose workers participated in the structured interviews; (4) structured interviews with 45 in-charges of private clinics; (5) 141 observations of client-provider interactions during consultations in 32 of the 45 private clinics; and (6) 125 exit interviews with clients seeking abortion services in the 32 private clinics. The interviews with key informants were transcribed, typed in Word and analysed for content using NVIVO software. Analysis involved coding of themes and categorizing the themes within a hierarchical framework of main and sub-themes. Quantitative data from structured interviews with pharmacy workers, simulated client visits to pharmacies, structured interviews with facility in-charges, observations of client-provider interactions, and exit interviews with clients were entered in EpiData and analysed using STATA. Analysis involved simple descriptive statistics including percentages, means and medians. 


\section{KEY FINDINGS}

\section{Abortion Environment: Perspectives of Key Informants}

- Although there has been progress in the legal and policy frameworks regarding abortion to increase the availability of safe and legal services, many service delivery challenges still persist. Limited dissemination of relevant documents and lack of clear and officially endorsed policy statements to guide public health facilities mean that there is a lack of awareness about the revised service standards and guidelines among service providers and the conditions under which safe abortion services can be legally provided.

- Although several non-governmental organizations and professional associations have developed curricula and supported training of service providers, especially from the private sector, on comprehensive abortion care, values clarification and attitude transformation and referrals, there is no standard training curriculum while skills gaps still persist among providers.

- Effective delivery of safe legal abortion services are further affected by societal stigma, poor access to appropriate information especially among those from marginalised settings, inadequate supply of drugs due to few established distribution channels, poor packaging and storage of relevant drugs, availability of counterfeits, and price distortion brought about by some of these challenges.

\section{Abortion Services in Private Pharmacies}

- Very few pharmacy workers (16\%) whose outlets provided abortion information or methods had been trained on the provision of the services with trainings focusing more on ensuring confidentiality and privacy of clients, history taking, and pain management, and less on the national standards and guidelines, recordkeeping and reporting, criteria for referral procedures and the recommended regimens for the combination of Mifepristone and Misoprostol.

- There was limited stocking of Misoprostol or Mifepristone even in pharmacies that provided abortion information or methods with only $18 \%$ of such pharmacies selling Misoprostol, $2 \%$ sold Mifepristone while none sold the combination of Mifepristone and Misoprostol. In addition, most of the pharmacies did not have the national standards and guidelines document on reducing maternal mortality and morbidity from unsafe abortion.

- There was limited knowledge of the correct regimen for Misoprostol only ( $22 \%$ of males and $16 \%$ of females) or for combination of Mifepristone and Misoprostol (13\% of males and 3\% of females) for pregnancies of various gestational ages among pharmacy workers who knew about the medications.

- Although nearly all pharmacy workers (97\%) felt that clients seeking Mifepristone and Misoprostol from pharmacies should have a prescription from a medical practitioner, only $11 \%$ indicated having ever denied clients abortion services because of lack of a prescription while the most common reasons for denial of services were religious or moral beliefs or lack of a trained provider.

- Pharmacy workers performed poorly on all indicators of interactions with simulated clients although the chances of asking about gestational age (55\% of interactions) and advising clients on where to obtain services for pregnancy termination (50\% of interactions) were higher than those of discussing family planning ( $12 \%$ of interactions), recommending family planning ( $9 \%$ of interactions), offering a method (1\% of interactions), or referring clients elsewhere for family planning ( $1 \%$ of interactions).

\section{Abortion Services in Private Clinics}

- The most common aspects related to the provision of abortion services that private providers had received in-service training on were infection prevention ( $78 \%$ of facilities), referral procedures ( $76 \%$ of facilities); and managing complications ( $76 \%$ of facilities) while the least aspects were the national standards and guidelines (60\% of facilities) and the legal and policy provisions regarding abortion (51\% of facilities).

- Availability of drugs and supplies for medical abortion was very limited (15\% of items) although the proportion of items that were in stock on the day of interview was similar to what were reported to be available. By contrast, facilities had most of the drugs and supplies for surgical abortion ( $81 \%$ of items) as well as for recovery, pain management and treatment of complications ( $85 \%$ of items) although the 
proportions of items that were in stock on the day of interview were lower than what was reported to be available.

- Although providers mostly cited health reasons (64\% of providers) and preservation of the mother's life (43\% of providers) as the common legal grounds for induced abortion, about a quarter (23\%) noted that induced abortion can be provided on request, which is contrary to existing laws and regulations. In addition, only about half $(49 \%)$ of providers whose facilities stocked Misoprostol mentioned the correct regimen for pregnancies of various gestational ages.

- Two-thirds (66\%) of the women seeking abortion services from private clinics were aged between 20 and 29 years, 64\% had at least secondary level education, 59\% were never married while 56\% had a previous pregnancy, with the majority of those who had more than one pregnancy (86\%) reporting having a previous abortion.

- More than half (59\%) of clients seeking abortion services had pregnancies of up to 9 weeks with the most common reason for seeking abortion services being that the pregnancy was unplanned (73\%) while other reasons included the need to continue with education (24\%), family pressure (14\%), and the need to continue with employment (14\%).

- Providers recommended the correct regimen for gestational age in only $31 \%$ of consultations in which medical abortion (Misoprostol alone or combination of Mifepristone and Misoprostol) was recommended. By contrast, providers recommended manual vacuum aspiration for $54 \%$ of pregnancies of up to 9 weeks, $59 \%$ of pregnancies above 9 and below 12 weeks, 31\% of pregnancies between 12 and 14 weeks, and 58\% of pregnancies over 14 weeks.

- Although nearly all (98\%) private clinics reported providing family planning information or methods, only $79 \%$ of the clients seeking abortion services were counselled on family planning while $48 \%$ were given a method. Besides, elements of family planning counselling were some of the least performed functions during consultations ( $40 \%$ of elements performed) while elements of interpersonal relationships such as courteous handling of clients were some of the most performed by providers ( $74 \%$ of elements performed).

- The majority of clients seeking abortion services (78\%) had previously used a family planning method, mostly male condom, oral pills, injectables, and emergency pill. Nearly two-thirds (63\%) chose a method on the day of visit, mostly injectables (40\%), male condoms (33\%), pills (20\%), implants (18\%), and IUCDs (18\%) while $60 \%$ of those who had a previously used a method chose a different method, mostly injectables, IUCD and implants.

- $\quad$ Prices of medical abortion drugs increased with higher gestation age of pregnancy although there were wide variations in the prices facilities charge for the methods, ranging from KSh. $90(\approx$ US \$1) to KSh. 7,000 ( $\approx$ US $\$ 82)$. Prices of surgical abortion methods also varied widely between facilities from KSh. $1,500(\approx U S \$ 18)$ to KSh. 15,000 ( $\approx$ US \$176).

\section{IMPLICATIONS}

- There is need for widespread and government-endorsed dissemination of the revised laws, policies, standards and guidelines on abortion services among health care providers for improved clarity regarding the provision of safe legal abortion services.

- There is need for a standard approach to improving the capacity of private providers to offer safe abortion services including having a standard training curriculum, which incorporates counselling on proper use of medication, family planning (especially long-term methods) and referrals for clients seeking abortion services.

- There is need to address some of the barriers to delivery and uptake of safe legal abortion services such as stigma and lack of access to information through public awareness especially regarding existing laws and policies on abortion and available services.

- There is need to ensure proper packaging of medical abortion products and to address the issue of counterfeits, for instance, by designing unique moisture-proof packages with bar codes that would be difficult to imitate to reduce the chances of users getting substandard products which can compromise their health. 
- There need to improve the supply chain to reduce stock-outs of essential drugs (especially combined Mifepristone and Misoprostol) in private pharmacies and clinics that provide abortion information or methods. 


\section{List of Abbreviations}

\begin{tabular}{|c|c|}
\hline AIDS & Acquired Immune Deficiency Syndrome \\
\hline ANMA & Africa Network for Medical Abortion \\
\hline DFID & Department for International Development \\
\hline FHOK & Family Health Options Kenya \\
\hline HIV & Human Immunodeficiency Virus \\
\hline IAGAS & Institute of Anthropology, Gender and African Studies \\
\hline ICPD & International Conference on Population and Development \\
\hline IPPF & International Planned Parenthood Federation \\
\hline IUCD & Intrauterine Contraceptive Device \\
\hline KEMRI & Kenya Medical Research Institute \\
\hline KCOA & Kenya Clinical Officers Association \\
\hline KMET & Kisumu Medical and Education Trust \\
\hline KNBS & Kenya National Bureau of Statistics \\
\hline KNH & Kenyatta National Hospital \\
\hline KNPP & Kenya National Pharmaceutical Policy \\
\hline KOGS & Kenya Obstetrical and Gynaecological Society \\
\hline MISA & Male Involvement in Safe Abortion \\
\hline $\mathrm{MOH}$ & Ministry of Health \\
\hline MSK & Marie Stopes Kenya \\
\hline MVA & Manual Vacuum Aspiration \\
\hline NACC & National AIDS Control Council \\
\hline NCPD & National Council for Population and Development \\
\hline NCST & National Council for Science and Technology \\
\hline NNAK & National Nurses Association of Kenya \\
\hline PATH & Program for Appropriate Technology in Health \\
\hline $\mathrm{PPH}$ & Postpartum Haemorrhage \\
\hline RHN & Reproductive Health Network \\
\hline RHRA & Reproductive Health and Rights Alliance \\
\hline STEP UP & Strengthening Evidence for Programming on Unintended Pregnancy \\
\hline STIS & Sexually Transmitted Infections \\
\hline UKaid & United Kingdom Agency for International Development \\
\hline VCAT & Values Clarification and Attitude Transformation \\
\hline VCT & Voluntary Counselling and Testing \\
\hline WHO & World Health Organization \\
\hline
\end{tabular}




\section{Background}

The World Health Organization (WHO) estimates that globally, approximately 210 million pregnancies occur each year with over 135 million resulting in live-born infants while the remaining 75 million end in stillbirth or (spontaneous or induced) abortion (WHO 2011). Available estimates further show that there were 213 million pregnancies worldwide in 2012 with 85 million (40 per cent) of them being unintended and half of the unintended pregnancies resulting in abortion (Sedgh et al. 2014). Most of the abortions are considered unsafe i.e. they are performed by untrained practitioners or provided in unhygienic settings (Singh et al. 2009; WHO 2004). Unsafe abortion accounts for 13 per cent $(47,000)$ of global maternal deaths worldwide while about 60 per cent of abortion-related deaths take place in Africa (Shah and Åhman 2010; United Nations 2010).

Globally, WHO estimated that there were 21.6 million unsafe abortions worldwide in 2008 with Africa having the second highest rate of unsafe abortion (28 per 1,000 women aged 15-44 years) after Latin America and the Caribbean which had a rate of 35 (WHO 2011). The rate of unsafe abortions was also higher in regions with restrictive compared to those with less restrictive abortion laws (WHO 2011). Studies show that although abortion is restricted in many countries in sub-Saharan Africa except for circumstances when the pregnancy endangers the life of the mother, abortion-related complications account for the majority of admissions to gynecological wards of hospitals in the region (Levandowski et al. 2012, 2013; Singh et al. 2005).

In Kenya, the maternal mortality ratio remains high at 488 deaths per 100,000 live births with 35 per cent of these deaths arising from unsafe abortion (Centre for Reproductive Rights 2010; Kenya National Bureau of Statistics [KNBS] and ICF Macro 2010; Ministry of Health 2003). A 2013 study that used patient-specific data for women who sought abortion-related care at health facilities found that the rate of induced abortions in the country was 48 per 1,000 women aged 15-49 years in 2012, higher than the 2002 rate of 45 per 1,000 women (Republic of Kenya 2013). The study further found that 37 per cent of the women seeking post-abortion care services had severe complications such as high fever, sepsis, shock and organ failure, indicating that abortion might have occurred under unsafe conditions (Republic of Kenya 2013).

Public debate on abortion and on proposals to liberalize the abortion law has been on-going for several years in Kenya (Brookman-Amissah and Moyo 2004). With the passing of a new Constitution in 2010, there was renewed interest in the right to health and the need to reduce the high levels of maternal morbidity and mortality arising from unsafe abortion in the country (Republic of Kenya 2010a; 2012). In 2012, for instance, the Government issued Standards and Guidelines for Reducing Morbidity and Maternal from Unsafe Abortion that emphasized professional non-judgmental counseling and provision of safe options in cases of unplanned, risky or unwanted pregnancies in line with the Constitution (Republic of Kenya 2012). The Constitution, on the other hand, stipulates that abortion is permissible if in the opinion of a trained health professional, there is need for emergency treatment, or the life or health of the mother is in danger or as determined by any other law (Republic of Kenya 2010a). Furthermore, Article 43(1)(a) of the Constitution states that every person has the right to the highest attainable standard of health, which includes the right to health care services, including reproductive health care (Republic of Kenya 2010a).

Apart from the legal and policy discourses, medical abortion using a combination treatment of Mifepristone and Misoprostol has been classified by WHO as a safe and effective method to stop a pregnancy up to 9 completed weeks since the last menstrual period i.e. during the first trimester (WHO 2012). Misoprostol is registered in Kenya as a multi-purpose drug whose indications include duodenal ulcer, gastric ulcer, treatment of incomplete abortion and miscarriage, treatment and prevention of post-partum haemorrhage $(\mathrm{PPH})$, treatment of intrauterine fatal death and cervical ripening. Mifepristone is also registered as a medication indicated for duodenal ulcer, gastric ulcer, cervical ripening and as a uterotonic drug to induce or increase uterine contractions. The availability of these two drugs in the country could replace surgical and non-surgical invasive methods that have previously been used to terminate pregnancies, both illegally and legally (Ong'ech et al. 2008).

In spite of the developments, there is limited understanding of the extent to which the changes have influenced the provision of medical abortion information and services in the country, the acceptability of the practice among providers and clients, and the content of care offered. This report presents findings from a study whose aim was to generate evidence on the current knowledge about medical abortion, availability of the services, as well as the nature of information exchange between clients and private providers (clinics and pharmacies). The study was conducted in three counties, namely, Nairobi, Kisumu, and Mombasa 
between April and June 2013. The counties were purposively selected based on availability of private clinics that were likely to provide medical abortion drugs. Private providers were targeted because access to information and services on medical abortion in Kenya is mainly through private practitioners while public health facilities mostly provide post-abortion care services (Wamugi et al. 2014). In addition, the counties have varied levels of reproductive health indicators such as contraceptive use (63\% in Nairobi, $62 \%$ in Kisumu and 55\% in Mombasa) and fertility (2.7 children per woman in Nairobi, 3.6 in Kisumu and 3.2 in Mombasa; KNBS et al. 2014).

The subsequent sections of this report are divided into three major parts based on the key institutions that were included in the study, namely, organizations with interest in reproductive health, private pharmacies, and private clinics. Each part provides a brief introduction including the objectives of gathering information from the institutions, methods, key findings and implications of the findings. The study obtained ethical approval and research clearance from the Institutional Review Board of the Population Council, the Ethics Review Committee of Kenya Medical Research Institute (KEMRI), the National Council for Science and Technology (NCST), and Marie Stopes International Ethical Review Committee. Written informed consent was obtained from all participants before data collection. 


\section{Abortion Environment in Kenya: Perspectives of Key Informants}

\section{INTRODUCTION}

Institutions working in the field of reproductive health can contribute to improved client outcomes through policy formulation, advocacy, program implementation, research to generate evidence to inform policy and programming, as well as funding of programs. With respect to abortion in Kenya, some of the institutions that have been at the forefront of promoting public debate on the issue since 2004 include an alliance formed by the Kenya Medical Association (KMA), the Kenya Obstetrics and Gynaecology Society (KOGS), the Federation of Women Lawyers and Ipas (Brookman-Amissah and Moyo 2004). The 2010 Constitution generated further debate on the issue especially regarding the meaning of reproductive health, trained health professional, or the phrase "as determined by any other law". For instance, the Constitution does not provide a definition of health or reproductive health but according to the 1994 International Conference on Population and Development (ICPD), reproductive health is a state of complete physical, mental and social well-being and not merely the absence of disease or infirmity in all matters relating to the reproductive system and to its functions and processes (United Nations 1994). Since Kenya was a signatory to the 1994 ICPD, the right to reproductive health care as enshrined in the Constitution can therefore be interpreted to include safe legal abortion, which is an important component of reproductive health services within a country (WHO 2004).

Apart from advocacy, other private sector institutions have focused on providing safe legal medical and surgical abortion services to clients. The Reproductive Health Network (RHN), for instance, is a network of public and private sector service providers committed to reducing maternal morbidity and mortality associated with unsafe abortion (Reproductive Health Network 2015). The Kenyan Chapter of Africa Network for Medical Abortion (ANMA) brings together private sector providers providing medical abortion. The institutions have also strengthened the referral systems by creating networks of gynaecologists, clinical officers, nurses and midwives. Informed by the Ministry of Health's (MOH) community strategy (Ministry of Health 2006), the institutions have engaged community health workers to identify and refer clients with a view to increasing access to safe abortion services in order to reduce maternal morbidity and mortality arising from unsafe abortions. There are also various community initiatives to increase access to reproductive health services. For example, the Male Involvement in Safe Abortion (MISA) project run by Kisumu Medical and Education Trust (KMET) in Kisumu trains men to be reproductive health champions in the community and to make referrals (KMET 2014). KMET also implements Sisterhood for Change project which trains teenage mothers in life skills and to advocate for their rights to enable them act as change agents in their communities (KMET 2014).

Other institutions have focused on enhancing the capacity of providers to address unsafe abortion through in-service training. Trainings have focused on comprehensive abortion care (including medical and surgical abortions) to improve the safety of abortion services, and on values clarification and attitude transformation (VCAT) to address the negative attitudes and beliefs about abortion. Organizations such as ANMA, Reproductive Health and Rights Alliance (RHRA), RHN and KOGS have been at the forefront in the development of training curricula and training of service providers. The cadres of providers trained are those that fall within the legal definition of a health professional including doctors, clinical officers, nurses and midwives. Most training has been for middle level providers (clinical officers, nurses and midwives) since they are the majority from whom poor women seek care. Mid-level providers are mostly trained to conduct abortions up to 12 weeks gestation, while an abortion in the second trimester can only be performed by doctors and gynaecologists. Some organizations (such as ANMA) have also started training pharmacists on making the right decisions when women seek to buy Misoprostol over the counter and also to refer the clients to the nearest ANMA member (ANMA Kenya 2014).

Based on the prevailing legal, policy and program environment regarding abortion, a key question is how the actors view the developments in the context of provision of quality care to clients. The prevailing environment may also determine whether the institutions allocate resources (human or financial) to influence policy and programs. The objectives of this component of the study were therefore:

1) To understand the contextual and programmatic factors that influence or are likely to influence the provision of medical abortion services in Kenya; and 
2) To explore the perspectives (positive and negative) of various stakeholders about abortion generally and the provision of medical abortion services specifically.

\section{METHODOLOGY}

A total of 19 key informant interviews were conducted with the senior managers from national and locallybased international institutions with interest in reproductive health in general and medical abortion in particular. The institutions were purposively selected to represent policy, program, research and donor interests. The institutions comprised the Ministry of Health, KOGS, the National Nurses Association of Kenya (NNAK), the Kenya Clinical Officers Association (KCOA), the University of Nairobi Department of Obstetrics and Gynaecology, Marie Stopes Kenya (MSK), Family Health Options Kenya (FHOK), the Kenya Chapter of the Africa Network for Medical Abortion (ANMA), the Reproductive Health Network (RHN), Reproductive Health and Rights Alliance (RHRA), Ipas, Woman Care Global, the International Planned Parenthood Federation (IPPF), Kenyatta National Hospital (KNH) and KMET. Each institution identified one senior manager who provided information on the state of medical abortion services in Kenya.

Key informants were persons aged 18 years and above. The interviews were conducted in English and were tape-recorded with the consent of the informants. The interviews were transcribed, typed in Word and analysed for content using NVIVO software. Analysis involved coding of themes and categorizing the themes within a hierarchical framework of main and sub-themes. The thematic framework was used to compare and contrast patterns of the themes between different key informants. The data from the interviews provide contextual information on the status of medical abortion in Kenya.

\section{FINDINGS}

Key informants reported that since the enactment of the 2010 Constitution, the abortion environment has been changing rapidly especially with respect to the legal and policy frameworks, training of service providers, service delivery, and availability of abortion commodities (equipment and drugs) although challenges remain.

\section{Legal and Policy Frameworks}

Key informants noted that there have been some developments in the legal and policy frameworks regarding abortion in Kenya. For instance, all key informants felt that the Standards and Guidelines for Reducing Morbidity and Mortality from Unsafe Abortion in Kenya was a good reference material that offered clear guidance for health workers who offer abortion services, as well as clarifying situations in which the health worker might not be willing to provide services due to personal beliefs. As one key informant noted:

So far I think it's [the Standards and Guidelines] a good one. I think its good enough to start off with. We can improve. It is giving the women and the service providers all the options. If you have an unwanted pregnancy, it gives you the option to adoption. The last part of it takes care of all the providers. The last one was only the doctors or a psychiatrist. If the providers are educated on it well, they can understand it well. I feel it's a good one. We now have a reference material.

Despite availability of the standards and guidelines document, key informants noted that it is yet to be disseminated widely, which has in turn affected its full implementation. $\mathrm{MOH}$ representatives stated that dissemination has been hampered by lack of adequate funds. In addition, the $\mathrm{MOH}$ has not issued a policy statement (through a circular or otherwise) that can be followed by public health facilities. These policy gaps have sometimes been exploited by the police to harass health workers known to provide abortion services legally. Key informants reported that:

Very few people even at our level know what the guidelines say. It was just last week we were planning to do a survey in [name of facility] to look at the efficacy and efficiency of the two tier levels on the use of Misoprostol and post-abortion care. When we applied for approval from the hospital ethical committee, the first comment they gave us was by asking who gave midwives the authority to offer post-abortion care. So I had to come back to the office and carry a hard copy. The issue is that people are not aware, there are documents and so we need to disseminate.

The legislation/policy needs to be very clear, and then we need to sensitize the health workers across the board for them to understand how the law protects them. It is a journey. But just saying the constitution has been passed and the standards and guidelines have been developed won't work. 


\section{Training of Service Providers}

Key informants reported that in spite of the provider trainings that have been undertaken by various organizations, major skills and performance gaps in safe abortion services among health care providers remain. These include:

- Poor knowledge of treatment protocols and drug dosages: This was largely because most health care providers have not read the protocols and drug specifications as outlined in the service standards and guidelines document.

- Poor counselling skills: Apart from nurses, other cadres of health care providers lack adequate counselling skills, which were attributed to lack of pre-service training.

- Poor surgical skills: Some doctors were reported to have the medical knowledge but lack practical skills for performing surgical abortion.

- Lack of skills in patient assessment specific to abortion: Many providers have skills in general patient assessment, but lack skills specific to abortion including physical examination.

- Poor skills in infection prevention and management of abortion complications: This is mostly among mid-level service providers (clinical officers, nurses and mid-wives).

- Lack of service integration: This is particularly with respect to linking women to other services such as family planning.

The informants reported that the skills and performance gaps could be addressed through well planned inservice trainings on safe abortion in the short term but will require to be incorporated in the pre-service curriculum in the long term. They further noted that in-service trainings should follow a standard curriculum to ensure that there is a common approach to provision of safe abortion services as opposed to a situation where trainings are done using different curricula developed by different institutions as has been the case.

\section{Service Delivery}

Key informants reported that, ideally, it should be possible for a woman to receive safe and legal abortion services in public health facilities. However, the focus in the public sector is still on the management of postabortion complications. There is still reluctance and apprehension to provide medical abortion services mainly due to the lack of a clear policy statement on abortion in the public sector. Key informants further noted that besides the limited dissemination of the standards and guidelines, provision of safe abortion services in public health facilities is hindered by negative provider attitudes and beliefs. It was reported that some health care workers decline to offer services due to their religious beliefs (i.e. conscientious objection) or the widespread social stigma associated with abortion. A health care provider reported that:

I do not mind what the Constitution says, my personal opinion is that we need to address. I think telling people the solution to irresponsible sexual behaviour is abortion [is wrong]. I think people are worried about pregnancy and not the consequences of unprotected sex, that is what we need to address. In emergency cases where there is rape and other cases, the services can be availed, but in situations where it is at will and in the era of HIV/AIDS, we need to be cautious.

Informants identified various challenges/barriers to women's ability to access safe medical abortion services to include:

- Stigma: Both the women seeking the services and the providers offering the services are stigmatized, for example, being referred to as 'baby killers'. Facilities identified to be offering safe abortion services are also stigmatized by the general public.

- Inadequate number of trained health providers: Although progress has been made with in-service training of health workers, the numbers are still insufficient to meet demand.

- Inadequate supply of drugs: Whereas Misoprostol and Mifepristone are registered, the distribution network is not yet well established. The drugs are readily available in major urban areas but scarce in small towns and rural areas.

- Cost: The price of the drugs in areas where there is limited supply was also reported to be out of reach of poor women and the youth. For instance, while the actual cost of Misoprostol could be as low as KSh. 20, it was reported that in some places it could cost as high as KSh. 1,000.

- Ignorance about the law: Many people are still not aware of the provisions of the Constitution regarding abortion services. Furthermore, others interpret the law narrowly in order to deny women services.

- Limited number of facilities that provide safe abortion services: There are not many publicly known facilities that provide the services, while those that do are mostly found in urban areas and are mainly privately owned. In addition, lack of clear policy statement has acted as a barrier to the 
provision of safe abortion services in public health facilities.

- Quality of care: This is affected by the secretive nature of providing abortion services; hence clients may obtain counterfeit commodities from people operating unregistered facilities. Providers' poor counselling skills as well as lack of awareness about service standards and guidelines also affect quality of care.

- Poor access to information: Women in urban slums and rural areas and especially younger women lack information on where to get safe abortion services and/or advice.

\section{Availability of Supplies, Equipment and Drugs}

Informants noted that the registration of medical abortion drugs-Misoprostol and Mifepristone-represented major progress towards addressing unsafe abortions in Kenya. Misoprostol has also been included in the essential drug list which makes it possible for public health facilities to procure it. Various stakeholders, including drug companies, non-governmental organizations and networks of providers, now procure and distribute abortion drugs and equipment to private health facilities that are in need. However, informants identified a number of challenges affecting the supply chain (importation, storage, distribution and marketing) of medical abortion commodities. They noted that the challenges are severe at the supply/distribution stage, as evidenced by the pricing of medical abortion drugs. As one informant noted:

As I said, the main challenge is the distribution outlets. If you are in [name of town], you need to go there and get the products at an affordable price. One time in [another town], I walked into a chemist and asked for Misoprostol, the lady told me I needed a prescription but I managed to convince her I was a health worker and she accepted. One tablet goes for KSh. 600 while a tablet here [name of facility] goes for KSh. 20, so you can imagine how many women are suffering. So the problem is at distribution and the cost.

The specific challenges with the supply chain that informants identified included:

- Importation bottlenecks: Similar to other medical products, challenges with importing medical abortion drugs and surgical abortion kits include paying for the products upfront, theft at customs, and delays in clearance by the customs authorities. These processes are time consuming and result in delays in getting the products to those who need them.

- High price of products: The price of abortion products was noted to be generally high and this is occasioned by poor supply and distribution channels. There are very few companies and organizations involved in the procurement of abortion commodities. The limited distribution channels in the country pushes the prices of commodities beyond the reach of health facilities and clients.

- Poor packaging and storage of drugs: Poor packaging of Misoprostol has been experienced, with some batches absorbing moisture, especially when poorly stored.

- Availability of counterfeits: Counterfeits are available for Misoprostol and manual vacuum aspiration (MVA) kits especially in Nairobi. The supply of counterfeits compromises the provision of safe abortion services since quality cannot be guaranteed. Counterfeits also affect the pricing of commodities and legitimate providers are likely to lose out.

\section{SUMMARY AND IMPLICATIONS}

\section{Summary of Findings}

- Although there has been progress in the legal and policy frameworks regarding abortion to increase the availability of safe and legal services, many service delivery challenges still persist. Limited dissemination of relevant documents and lack of clear and officially endorsed policy statements to guide public health facilities mean that there is a lack of awareness about the revised service standards and guidelines among service providers and the conditions under which safe abortion services can be legally provided.

- Although several non-governmental organizations and professional associations have developed curricula and supported training of service providers, especially from the private sector, on comprehensive abortion care, values clarification and attitude transformation and referrals, there is no standard training curriculum while skills gaps still persist among providers.

- Effective delivery of safe legal abortion services are further affected by societal stigma, poor access to appropriate information especially among those from marginalised settings, inadequate supply of drugs due to few established distribution channels, poor packaging and storage of relevant drugs, availability 
of counterfeits, and price distortion brought about by some of these challenges.

\section{Implications}

- There is need for widespread and government-endorsed dissemination of the revised laws, policies, standards and guidelines on abortion services among health care providers for improved clarity regarding the provision of safe legal abortion services.

- The finding that gaps still exist with respect to provider skills despite trainings conducted by different partners suggest the need for a standard approach to improving the capacity of providers to offer safe abortion services including having a standard training curriculum.

- There is need to address some of the barriers to delivery and uptake of safe legal abortion services such as stigma and lack of access to information through public awareness especially regarding existing laws and policies on abortion and available services.

- There is need to ensure proper packaging of medical abortion products and to address the issue of counterfeits, for instance, by designing unique moisture-proof packages with bar codes that would be difficult to imitate to reduce the chances of users getting substandard products which can compromise their health. 


\section{Abortion Services in Private Pharmacies}

\section{INTRODUCTION}

Private pharmacies in Kenya play a critical role in ensuring access to essential medicines by those in need. The 2010 Kenya National Pharmaceutical Policy (KNPP) recognizes the right to access essential medicines especially by vulnerable population groups as part of the fundamental right to health as enshrined in the Constitution (Republic of Kenya 2010b). According to the policy, registered pharmacists and enrolled pharmaceutical technologists are the only cadres of health personnel qualified to dispense medicines and operate private pharmacies in the country (Republic of Kenya 2010b). However, private pharmacies face challenges that might affect the way consumers benefit from essential medicines. From a public health perspective, private pharmacies may lack the incentives to take up important steps in promoting rational decision-making by consumers including counselling on proper use of medicines or providing referrals for appropriate care. This could be attributed to the nature of training for pharmacists (which may not include the provision of public health information and services) and the fact that interactions with clients at private pharmacies are mostly with frontline staff some of whom lack formal training in health service provision (PATH 2004). Private pharmacy providers are further faced with the challenge of balancing operations as a business establishment and performing the role of health service providers (Skibiak et al. 2001; PATH 2004).

The registration of Mifepristone and Misoprostol in Kenya made them part of the essential drugs list for distribution and sale through registered outlets including private pharmacies. The medications are distributed to registered private pharmacies and clinics by recognized distributors including Marie Stopes International for Misoprostol and Maxima Pharmaceuticals Limited for Mifepristone. The medications are registered for sale over the counter with prescriptions from a medical practitioner. Challenges associated with medicines being sold as commodities as well as those faced by private pharmacies may affect the way the two medications are sold to and used by consumers. There is, however, limited understanding of private pharmacy providers' knowledge of the medications and existing regulations, how they dispense the medications and how they generally interact with clients seeking abortion services. The objectives of this component of the study were:

1) To assess the availability of Mifepristone and Misoprostol or other abortifacient as well as the skills and practices of workers in private pharmacies;

2) To examine the knowledge and attitudes of private pharmacy workers regarding Mifepristone and Misoprostol or other abortifacients; and

3) To explore the information given to clients seeking medical abortion services at private pharmacies.

\section{METHODOLOGY}

This component of the study involved structured interviews with private pharmacy workers and simulated client visits to the pharmacies.

\section{Interviews with Pharmacy Workers}

In each county, 100 pharmacies were randomly sampled from the list of all registered private pharmacies. It is common for pharmacies and chains of pharmacies to be owned by one proprietor who employs workers to provide services to clients. For each sampled pharmacy, the owner was approached to provide written informed consent for his/her pharmacy to be included in the study. Of the 300 sampled pharmacies, owners of 274 granted consent (82 in Nairobi, 93 in Kisumu and 99 in Mombasa). Subsequently, trained research assistants visited these 274 pharmacies to conduct interviews with the pharmacy workers. One most senior pharmacy worker was interviewed in each pharmacy. To be eligible for interview, the pharmacy worker had to be actively involved in dispensing drugs, should have worked for at least six months at the pharmacy, and gave individual written informed consent. Interviews were completed with 235 pharmacy workers (82 in Nairobi, 80 in Kisumu and 73 in Mombasa), 36 refused (11 in Kisumu and 25 in Mombasa) while 3 interviews were only partially completed ( 2 in Kisumu and 1 in Mombasa).

The interviews aimed at determining the availability of medical abortion services as well as knowledge, attitudes and practices of the workers regarding the services. Information was captured on the background 
characteristics of pharmacy workers (sex, age, education level and training), their knowledge of medical abortion products and regimens, service provision practices at the pharmacy, and the cost of Misoprostol and Mifepristone. Pharmacy workers were approximately equally male and female, with an average age of 31 years (range of 22 to 58 years). Nearly all (97\%) had secondary education and above. The majority (56\%) worked at pharmacies in peri-urban areas, 34\% were in pharmacies in the central business district of each urban centre, while $10 \%$ were in rural areas. The majority (80\%) were employees and $92 \%$ reported that they were trained to dispense medicines.

\section{Simulated Client Visits}

The simulated client approach was used to understand service provision practices followed for clients seeking abortion services at pharmacies. Simulated clients were females aged between 18 and 31 years, and trained to assume one of the following four specific profiles of clients seeking medical abortion services from a pharmacy:

- Scenario 1: A woman specifically wanting to purchase Misoprostol without stating a reason;

- Scenario 2: A woman specifically wanting to purchase Misoprostol and stating that the reason is to end a pregnancy without stating the gestation period;

- Scenario 3: A woman seeking any medication to end an 8-week pregnancy; and

- Scenario 4: A woman seeking any medication to end a 12-week pregnancy (i.e. after the recommended threshold gestation).

In each county, about half of the pharmacies whose workers were interviewed were visited by simulated clients. A total of 401 simulated client visits were made (136 in 53 pharmacies in Nairobi, 134 in 49 pharmacies in Kisumu, and 131 in 40 pharmacies in Mombasa). Each pharmacy was visited an average of three times (minimum one, maximum 4) on different dates at least one week after the structured interviews with the pharmacy workers, over a period of one month. The minimum time period between visits was three days. No pharmacy was visited more than once by the same simulated client. Within one hour of each visit, the simulated client completed a structured questionnaire to record details of their interaction with the pharmacy workers including any information and product they were given. The visits were equally distributed among the four scenarios, i.e. 100 visits per scenario.

\section{Data Analysis}

Data from structured interviews with pharmacy workers and simulated client visits were entered in EpiData and analysed using STATA. Analysis involved simple descriptive statistics including percentages, means and medians. For simulated client data, Chi-square tests were performed to determine if differences between scenarios were statistically significant.

\section{RESULTS}

\section{Staffing Levels and Staff Training}

The median number of staff at the pharmacies was 8 with a minimum of 1 and maximum of 8 persons. Only $16 \%$ of the pharmacy workers who reported that their outlets provided abortion services (information or methods) had been trained on the provision of the services with wide variations between counties (52\% in Nairobi, $15 \%$ in Kisumu and $2 \%$ in Mombasa). In addition, $10 \%$ of the pharmacy workers who reported that their outlets did not provide abortion services indicated that they had been trained to provide the services (12\% in Nairobi, 11\% in Kisumu and none in Mombasa). Pharmacy workers who indicated that they had been trained were asked to specify the aspects in which they had been trained (Figure 1). Most had been trained in ensuring confidentiality and privacy of clients (97\%), history taking (91\%), and pain management (88\%), and relatively few had been trained in the national standards and guidelines (34\%), record-keeping and reporting (38\%) and criteria for referral procedures (38\%). 
Figure 1: Per cent distribution of pharmacy workers who had been trained on provision of abortion services by training specific aspects

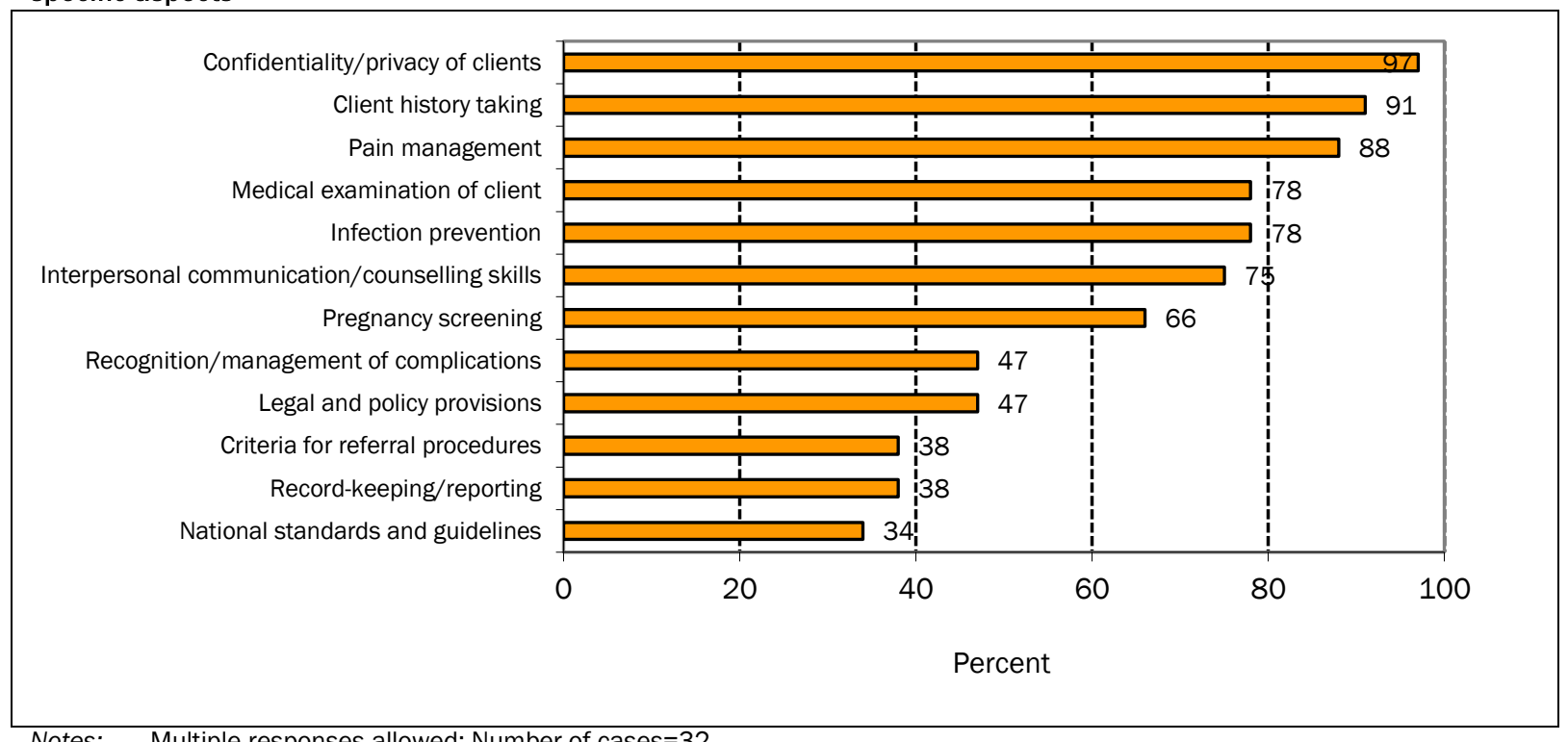

Misoprostol-only regimen was the most common method that pharmacy workers had been trained in, followed by MVA, dilatation and curettage, and dilatation and evacuation (Figure 2). Less than 10\% of the trained pharmacy workers had been trained in Mifepristone-only (6\%) or the recommended combination of Mifepristone and Misoprostol regimens (9\%).

Figure 2: Per cent distribution of pharmacy workers who had been trained on provision of abortion services by specific methods

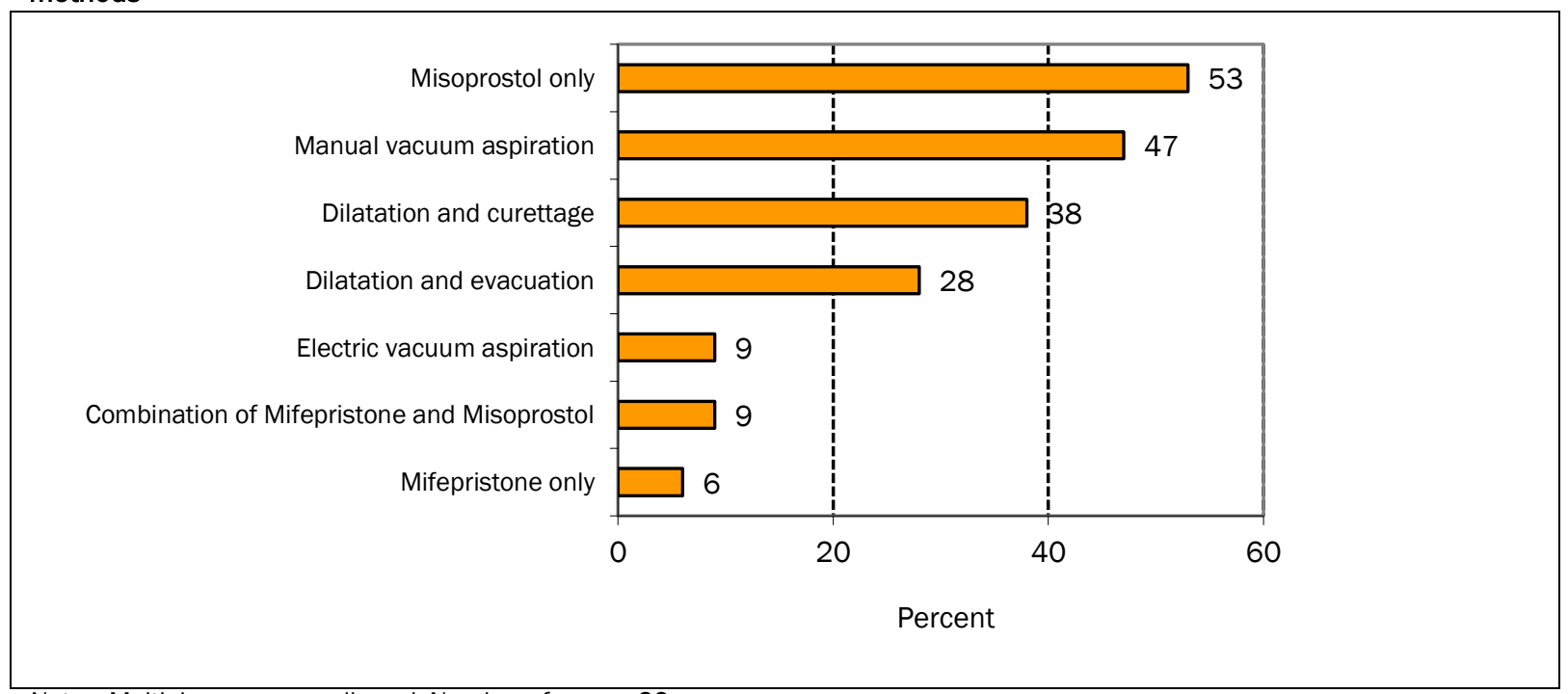

Notes: Multiple responses allowed; Number of cases=32.

\section{Availability of Abortion Services}

More than half (58\%) of the pharmacy workers interviewed indicated that they provided advice or information on pregnancy termination to clients seeking the services although there were wide variations by county (65\% in Kisumu, 29\% in Nairobi and 84\% in Mombasa). The most commonly provided information were referral to a health facility $(71 \%)$, continuing with the pregnancy $(60 \%)$, and seeking counselling services on how to manage the pregnancy (36\%). Only $4 \%$ of the pharmacy workers reported that they provided methods of pregnancy termination to clients seeking the services (1\% each in Kisumu and Mombasa and $9 \%$ in Nairobi). Nine out of ten provided Misoprostol only. Ninety five per cent of the pharmacy workers whose outlets provided abortion information or methods indicated that they sold family planning methods as well, which 
provides an opportunity to offer such clients the methods. The most commonly sold methods in these outlets were pills (95\%), male condoms (91\%), emergency contraceptives (89\%), and the 3-month injectables (75\%).

Among pharmacies whose workers reported that they provided abortion information or methods, $18 \%$ indicated that they sold Misoprostol only, 2\% sold Mifepristone only while none sold the combination of Mifepristone and Misoprostol. The most commonly reported reasons for selling the medications were for controlling peptic ulcers (68\%), labour induction (28\%), controlling postpartum haemorrhage (24\%), and treating incomplete abortion (12\%).

About two-thirds (67\%) of the pharmacy workers who reported that they did not provide abortion information or methods indicated that clients asked for those services. In most cases, they referred clients elsewhere (49\%) or advised them against procuring an abortion (40\%). Those who reported referring clients elsewhere mostly referred them to private health facilities (78\%). Others made referrals to public health facilities (54\%) and general practitioners (8\%).

\section{Availability of Drugs and Supplies}

Among pharmacies that provided information or methods on abortion, the most commonly available supplies were policy on confidentiality of clients (89\%), policy on record-keeping and reporting (87\%), Misoprostol (66\%), and referral mechanisms (52\%). The least available items were Mifepristone (2\%), WHO Technical and Policy Guidance on Safe Abortion and the National Standards and Guidelines for abortion care (Figure 3).

Figure 3: Per cent distribution of pharmacies providing abortion information or methods by availability of drugs and supplies

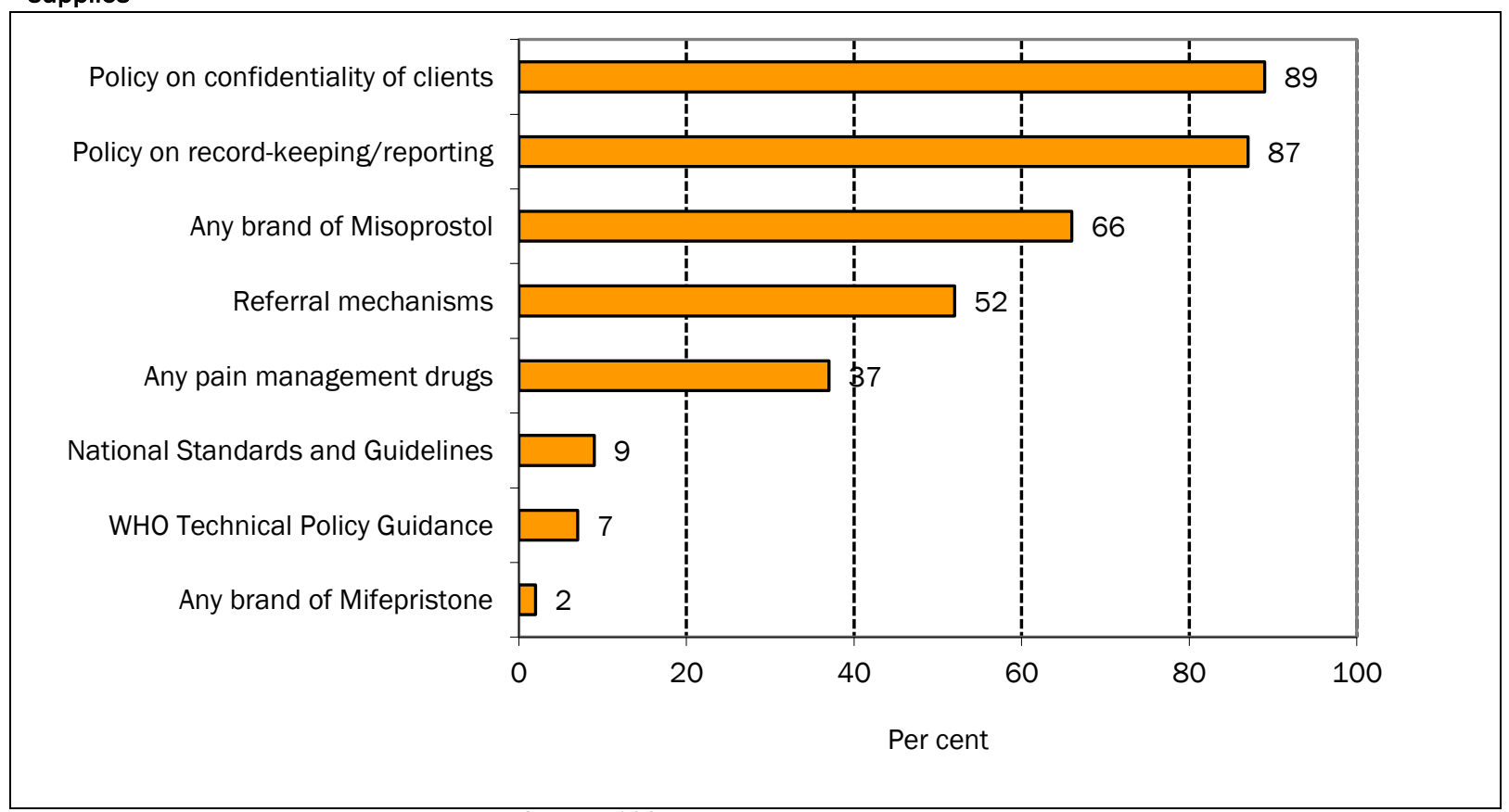

Notes: Multiple responses allowed; Number of cases=138. 


\section{Prices of Medical Abortion Methods}

The average price of Misoprostol based on information obtained from pharmacy workers ranged from KSh. 74 ( $\approx$ US \$0.87) to KSh. 530 ( $\approx$ US \$6) depending on the brand (Table 1). The average price of Mifepristone was KSh. 73 ( $\approx$ US $\$ 0.86)$. However, the prices quoted for simulated clients were much higher, ranging from KSh. 391 ( $\approx$ US $\$ 4.60$ ) to KSh. 2,116 ( US \$24) depending on the scenario presented (Table 1).

\begin{tabular}{|c|c|c|c|c|}
\hline \multirow[b]{2}{*}{ Method } & $\begin{array}{r}\text { Minimum } \\
(\mathrm{KSH})\end{array}$ & $\begin{array}{r}\text { Maximum } \\
(\mathrm{KSH})\end{array}$ & $\begin{array}{r}\text { Median } \\
(\mathrm{KSH})\end{array}$ & $\begin{array}{r}\text { Number of } \\
\text { pharmacies }\end{array}$ \\
\hline & \multicolumn{4}{|c|}{ Prices given by pharmacy workers } \\
\hline \multicolumn{5}{|l|}{ Brands of Misoprostol } \\
\hline Misoclear & 30 & 300 & 60 & 38 \\
\hline Cytotec-pharmacia UK & 35 & 350 & 100 & 54 \\
\hline Isovent & 50 & 120 & 60 & 9 \\
\hline Arthrotec & 50 & 2,890 & 55 & 6 \\
\hline \multirow[t]{2}{*}{ Mifepristone Linepharma $200 \mathrm{mg}$} & 65 & 80 & 73 & 2 \\
\hline & \multicolumn{4}{|c|}{ Prices quoted for simulated clients } \\
\hline \multicolumn{5}{|l|}{ Misoprostol only } \\
\hline Scenario 1 & 50 & 3,000 & 100 & 23 \\
\hline Scenario 2 & 200 & 4,000 & 800 & 7 \\
\hline Scenario 3 & 280 & 3,500 & 2,500 & 5 \\
\hline Scenario 4 & 320 & 5,000 & 1,000 & 11 \\
\hline All four scenarios & 50 & 5,000 & 450 & 46 \\
\hline Mifepristone only & 400 & 1,000 & 700 & 2 \\
\hline \multicolumn{5}{|c|}{ Notes: $\quad$ Standard deviations for means are in parentheses; KSH: Kenya shilling (1 USD $\approx \mathrm{KSH} .85$ ). } \\
\hline
\end{tabular}

\section{Knowledge and Attitudes of Pharmacy Workers}

Misoprostol alone was the most commonly known abortion medication among private pharmacy providers ( $86 \%$ of males and $76 \%$ of females) followed by Mifepristone alone ( $46 \%$ of males and $28 \%$ of females) while the combination of Mifepristone and Misoprostol was the least known (Figure 4). However, only $22 \%$ of males $(\mathrm{N}=103)$ and $16 \%$ of females $(\mathrm{N}=86)$ who had heard of the medications mentioned the correct regimen for Misoprostol only for pregnancies of various gestational ages. Similarly, only $13 \%$ of males $(N=55)$ and $3 \%$ of females ( $\mathrm{N}=32)$ mentioned the correct regimen for combination of Mifepristone and Misoprostol (Figure 4). A small proportion (3\%) of the pharmacy workers felt that clients seeking abortion services should be able to get the drugs from pharmacies without a prescription.

Figure 4: Per cent distribution of pharmacy workers by knowledge and attitudes regarding abortion

Clients should be able to get abortion drugs without prescription




\section{Service Provision Practices}

Slightly more than a quarter (27\%) of pharmacy workers whose outlets provided abortion information or methods reported ever denying clients the services (32\% of males and $20 \%$ of females; Table 2). The most common reasons for denying clients the services were religious or moral beliefs (57\%), lack of trained provider (38\%), lack of permission from third parties (19\%), lack of appropriate equipment (14\%), and lack of prescription from a medical practitioner (11\%). In addition, 35\% of pharmacy workers whose outlets provided abortion information or methods indicated that they screened clients (31\% of males and 40\% of females) while $7 \%$ advised clients to return for follow-up visits (8\% of males and $7 \%$ of females; Table 2 ). Screening of clients mostly involved asking for reasons of seeking to terminate pregnancy, asking about gestational age of the pregnancy, asking about client's background characteristics, conducting medical examination, asking for prescription, asking about medical history, and asking for proof of permission from third parties (not shown).

\begin{tabular}{|l|r|r|r|}
\hline Table 2: Per cent distribution of pharmacy workers by practices regarding abortion \\
\hline Indicator & $\begin{array}{r}\text { Male } \\
(\%)\end{array}$ & $\begin{array}{r}\text { Female } \\
(\%)\end{array}$ & $\begin{array}{r}\text { Both sexes } \\
(\%)\end{array}$ \\
\hline Instances of pharmacy denying abortion clients & 32.1 & 20.0 & 26.8 \\
services $^{a}$ & $(\mathrm{~N}=78)$ & $(\mathrm{N}=60)$ & $(\mathrm{N}=12)$ \\
\hline Reasons for denying abortion clients services & $(\mathrm{N}=25)$ & 25.0 & $(\mathrm{~N}=37)$ \\
\hline Lack of prescription & 4.0 & 8.3 & 10.8 \\
\hline Lack of permission from third parties & 24.0 & 8.3 & 18.9 \\
\hline Client could not afford to pay & 4.0 & 0.0 & 5.4 \\
\hline Stock-out of essential drugs & 8.0 & 16.7 & 5.4 \\
\hline Lack of appropriate equipment & 12.0 & 33.3 & 13.5 \\
\hline No trained provider & 40.0 & 41.7 & 37.8 \\
\hline Religious/moral beliefs & 64.0 & $(\mathrm{~N}=60)$ & 56.8 \\
\hline Providera & $(\mathrm{N}=78)$ & 40.0 & $(\mathrm{~N}=138)$ \\
\hline Screens clients seeking abortion services & 30.8 & 6.7 & 34.8 \\
\hline Advises clients to return for follow-up & 7.7 & & 7.3 \\
\hline Notes: aAmong pharmacies providing information or services on abortion. & & \\
\hline
\end{tabular}

With respect to interactions with simulated clients, there were significant variations in the practices of pharmacy workers by the scenario presented. In particular, the proportion of visits for which pharmacy workers asked about the last menstrual period, gestational age, medical history, reasons for pregnancy termination, and proof of permission from third parties were highest when simulated clients sought medication to terminate a three-month pregnancy (scenario 4) and lowest when they just asked for Misoprostol without stating reason (scenario 1; Table 3). Similarly, the proportion of visits for which pharmacy workers advised clients to continue with the pregnancy or gave information about where to obtain pregnancy termination services, available methods of pregnancy termination, and surgical abortion methods were highest under scenario 4 and lowest under scenario 1. By contrast, the proportion of visits for which providers asked for prescriptions from a medical practitioner and discussed medical abortion methods was highest under scenario 1 (Table 3).

For all visits combined, pharmacy workers performed poorly on all indicators; the highest scores were for asking about gestational age (55\%) and advising clients on where to obtain services for pregnancy termination (50\%). In addition, despite the fact that most pharmacies providing abortion information or services also sold family planning methods, family planning was discussed with simulated clients in only $12 \%$ of the visits (Table 3 ). Similarly, pharmacy workers recommended family planning in $9 \%$ of visits, offered a method in $1 \%$ of visits, and referred clients elsewhere for family planning in $1 \%$ of visits (Table 3 ). 


\begin{tabular}{|c|c|c|c|c|c|}
\hline Indicator & $\begin{array}{r}\text { Client asked for } \\
\text { Misoprostol without } \\
\text { stating reason: } \\
\text { scenario } 1 \\
(\%)\end{array}$ & $\begin{array}{r}\text { Client sought help to } \\
\text { terminate pregnancy } \\
\text { without stating } \\
\text { gestational age: } \\
\text { scenario } 2 \text { (\%) }\end{array}$ & $\begin{array}{r}\text { Client sought } \\
\text { medication to } \\
\text { terminate 2-month } \\
\text { pregnancy: scenario } \\
3(\%)\end{array}$ & $\begin{array}{r}\text { Client sought } \\
\text { medication to } \\
\text { terminate 3-month } \\
\text { pregnancy: scenario } 4 \\
(\%)\end{array}$ & $\begin{array}{r}\text { All four scenarios } \\
(\%)\end{array}$ \\
\hline \multicolumn{6}{|l|}{ History-taking and medical examination } \\
\hline Provider asked about last menstrual period & 6.9 & 39.0 & 32.7 & $74.8 * *$ & 38.2 \\
\hline Provider asked about gestational age of pregnancy & 28.7 & 50.0 & 75.3 & $64.7 * *$ & 54.6 \\
\hline Provider asked about medical history & 0.0 & 6.0 & 2.0 & $18.2^{* *}$ & 6.5 \\
\hline Provider asked about reasons for terminating pregnancy & 13.9 & 57.0 & 48.5 & $65.7 * *$ & 46.1 \\
\hline Provider asked about prescription & 44.6 & 24.0 & 13.9 & $33.3 * *$ & 28.9 \\
\hline Provider asked about permission from third parties & 0.0 & 3.0 & 12.9 & $28.3 * *$ & 11.0 \\
\hline Provider conducted medical examination & 3.0 & 4.0 & 5.0 & 7.1 & 4.7 \\
\hline \multicolumn{6}{|l|}{ Counselling } \\
\hline Provider advised to continue with pregnancy & 9.9 & 45.0 & 24.8 & $59.6 * *$ & 34.7 \\
\hline Provider advised to seek counselling before abortion & 16.8 & 12.0 & 6.9 & $28.3^{* *}$ & 16.0 \\
\hline Provider advised where to obtain abortion services & 27.7 & 50.0 & 53.7 & 69.7 ** & 50.1 \\
\hline Provider advised about available abortion methods & 6.9 & 37.0 & 28.7 & $50.5^{* *}$ & 30.7 \\
\hline Provider discussed any surgical abortion method & 5.0 & 29.0 & 26.7 & $50.5^{* *}$ & 27.7 \\
\hline Provider discussed any medical abortion method & 48.5 & 19.0 & 14.9 & $20.2 * *$ & 25.7 \\
\hline Provider discussed family planning & 5.9 & 7.0 & 18.8 & 16.2 ** & 12.0 \\
\hline Provider recommended family planning & 5.0 & 7.0 & 10.9 & 12.1 & 8.7 \\
\hline Provider referred client elsewhere for family planning & 0.0 & 1.0 & 0.0 & $3.0^{*}$ & 1.0 \\
\hline \multicolumn{6}{|l|}{ Services } \\
\hline Provider offered surgical abortion method & 2.0 & 5.0 & 11.9 & $11.1^{*}$ & 7.5 \\
\hline Provider offered medical abortion method & 5.9 & 10.0 & 5.9 & 12.1 & 8.5 \\
\hline Provider offered medication to manage pain & 2.0 & 1.0 & 11.9 & $6.1 * *$ & 5.2 \\
\hline Provider offered medication for complications & 2.0 & 1.0 & 12.9 & $5.1 * *$ & 5.2 \\
\hline Provider offered family planning method & 0.0 & 1.0 & 0.0 & 1.0 & 0.5 \\
\hline
\end{tabular}




\section{SUMMARY AND IMPLICATIONS}

\section{Summary of Findings}

- Very few pharmacy workers (16\%) whose outlets provided abortion information or methods had been trained on the provision of the services with trainings focusing more on ensuring confidentiality and privacy of clients, history taking, and pain management, and less on the national standards and guidelines, record-keeping and reporting, criteria for referral procedures and the recommended regimens for combination of Mifepristone and Misoprostol.

- There was limited stocking of Misoprostol or Mifepristone even in pharmacies that provided abortion information or methods with only $18 \%$ of such pharmacies selling Misoprostol, $2 \%$ sold Mifepristone while none sold the combination of Mifepristone and Misoprostol. In addition, most of the pharmacies did not have the national standards and guidelines document on reducing maternal mortality and morbidity from unsafe abortion.

- There was limited knowledge of the correct regimen for Misoprostol only ( $22 \%$ of males and $16 \%$ of females) or for combination of Mifepristone and Misoprostol (13\% of males and 3\% of females) for pregnancies of various gestational ages among pharmacy workers who knew about the medications.

- Although nearly all pharmacy workers (97\%) felt that clients seeking Mifepristone and Misoprostol from pharmacies should have a prescription from a medical practitioner, only $11 \%$ indicated having ever denied clients abortion services because of lack of a prescription while the most common reasons for denial of services were religious or moral beliefs or lack of a trained provider.

- Pharmacy workers performed poorly on all indicators of interactions with simulated clients although the chances of asking about gestational age (55\% of interactions) and advising clients on where to obtain services for pregnancy termination (50\% of interactions) were higher than those of discussing family planning (12\% of interactions), recommending family planning ( $9 \%$ of interactions), offering a method ( $1 \%$ of interactions), or referring clients elsewhere for family planning ( $1 \%$ of interactions).

\section{Implications}

- There is need to improve the capacity of pharmacy workers to offer appropriate information including proper use of medication, family planning and referrals to clients seeking abortion services.

- There is need to improve the supply chain to reduce stock-outs of essential drugs (especially combined Mifepristone and Misoprostol) in private pharmacies that provide abortion information or methods.

- There is need for widespread dissemination of the existing policies and guidelines among pharmacy workers to ensure that they provide services within existing regulations. 


\section{Abortion Services in Private Clinics}

\section{INTRODUCTION}

Private clinics in Kenya are operated by the cadres of providers that fall within the legal definition of a health professional including doctors, clinical officers, nurses and midwives. The clinics are registered by the Kenya Medical Practitioners and Dentists Board, the Clinical Officers Council or the Nursing Council of Kenya depending on the qualification of the provider operating the clinic. It is also common for private providers to be part of a network or franchise that aims at improving institutional sustainability of the clinics and the quality of care that they provide. In spite of the regulatory and institutional oversight available for private clinics in the county, the nature of care provided at the outlets may still be affected by other factors such as the resources at the disposal of the provider, availability of appropriate services, choices that clients make, technical competence of providers as well as how they interact with clients including mechanisms for follow-up (Bruce 1990).

In the context of abortion services, care at private clinics may be affected by some of the challenges identified by key informants (see section on "Abortion Environment") including inadequate training, limited awareness about relevant policies and guidelines, poor supply and distribution chain for essential medicines, and the social stigma associated with the practice. However, little is known about the provision of medical abortion in private clinics in the country, the acceptability of the practice among providers and clients, as well as the content of care given to clients. The objectives of this component of the study were:

1) To assess the availability of Mifepristone and Misoprostol or other abortifacient as well as the skills and practices of providers in private clinics;

2) To examine the knowledge and attitudes of providers in private clinics regarding Mifepristone and Misoprostol or other abortifacients;

3) To determine the characteristics, choices and perceptions of clients seeking abortion services from private clinics; and

4) To explore the quality of care given to clients seeking abortion services from private clinics.

\section{METHODOLOGY}

This component of the study involved structured interviews with in-charges (managers) of private clinics, observations of client-provider interactions during consultations, and structured exit interviews with clients seeking abortion services.

\section{Interviews with Facility In-charges}

Structured interviews were conducted with facility in-charges of 45 private clinics that provide abortion services (11 in Kisumu, 18 in Nairobi, and 16 in Mombasa). The facilities were randomly sampled from among those that were members of the Reproductive Health Network and/or the AMUA Franchise that is managed by Marie Stopes Kenya. A minimum of 10 facilities were targeted in each County. The interviews with the in-charges included an inventory to determine the available infrastructure, staffing levels and skills mix, equipment, commodities, and supplies needed for surgical and medical abortion services. The facility in-charges were also asked about their knowledge and practices as well as the prices of abortion services available at the facility. Almost one-half (47\%) of the in-charges were nurses or midwives, 36\% were clinical officers, $9 \%$ were gynaecologists, and $9 \%$ were community health workers. Two-thirds of in-charges were male. On average, the providers had worked in health care for 19 years, although females had worked longer (average of 24 years) compared to males (average of 16 years).The providers had worked at the facilities where they were interviewed for an average of 9 years with females having worked slightly longer (11 and 7 years respectively).

\section{Observations of Client-Provider Interactions}

Observations of client-provider interactions during consultations were in conducted in private clinics with clients and providers who had given their consent to be observed during the provision of a medical abortion procedure. A total of 141 observations were conducted in 32 out of the 45 private clinics that were included in the study (62 in 11 clinics in Kisumu, 58 in 12 clinics in Nairobi and 21 in 9 clinics in Mombasa). Two observations were partially completed (1 in Kisumu and 1 in Mombasa) because the clients needed referrals to higher level facilities. The observations were conducted by trained nurses to determine the nature and quality of services that clients received. The nurses used a 
structured checklist adapted from the WHO Technical and Policy Guidance on Safe Abortion (WHO 2012) and the National Standards and Guidelines for Reducing Morbidity and Mortality from Unsafe Abortion in Kenya (Republic of Kenya 2012). They observed aspects of history taking, pre-procedure counselling, medical examination, provision of medical abortion, and post-abortion care information provided to clients.

\section{Client Exit Interviews}

Immediately after the observations, consenting clients were requested to participate in an exit interview to determine their perceptions of the services provided and their overall impression of the provider's behaviour during the consultation. Interviews were completed with 125 clients (48 in 11 clinics in Kisumu, 56 in 12 clinics in Nairobi and 21 in 9 clinics in Mombasa). Six interviews were partially completed and eight clients who were observed during the consultation refused the interview. Information was collected on their background characteristics (such as age, education level, marital status, religious affiliation, and household assets and amenities), childbearing experiences and intentions, family planning knowledge and use, and perceptions about the services received. The interviews were conducted in English, Kiswahili or a mixture of both depending on the clients' preference by a research assistant who was paired with the nurse conducting the observations.

\section{Data Analysis}

All data were entered in EpiData and analysed using STATA. Analysis involved simple descriptive statistics including percentages, means and medians. Composite scores were computed to determine availability of drugs and supplies as well as the quality of care that clients received. The results are presented in the form of the fraction of elements that were available in the clinics or that were performed by providers during interactions with clients. Tables A1 and A2 in the Appendix present the list of items that were used to compute the scores for service availability and quality of care respectively.

\section{RESULTS}

\section{Staffing Levels and Staff Training}

The clinics had, on average, 4 medical and 1 support staff, with facilities in Nairobi having the highest median number of providers, followed by those in Mombasa and Kisumu (Table 4). However, facilities had on average only 1 staff member trained on medical abortion, comprehensive post-abortion care or family planning, while none was trained on values clarification and attitude transformation. Facilities in Kisumu had higher numbers of staff members trained on medical abortion and family planning (Table 4). Further analysis showed that the most common aspects related to the provision of abortion services that clinic staff had received in-service training on were infection prevention (78\% of facilities), referral procedures (76\%); and managing complications (76\%; not shown). The least aspects that staff had been trained on were the national standards and guidelines (60\% of facilities) and the legal and policy provisions regarding abortion (51\%; not shown). Other aspects that staff had been trained on included pregnancy screening $(67 \%$ of facilities), communication/counselling $(69 \%)$, medical examination of clients $(69 \%)$, history taking (71\%), pain management (71\%), record-keeping/reporting (71\%), and confidentiality/privacy of clients (73\%; not shown).

\begin{tabular}{|c|c|c|c|c|}
\hline Indicator & $\begin{array}{r}\text { Kisumu } \\
(\mathrm{N}=11)\end{array}$ & $\begin{array}{l}\text { Nairobi } \\
(\mathrm{N}=18)\end{array}$ & $\begin{array}{r}\text { Mombasa } \\
(\mathrm{N}=16)\end{array}$ & $\begin{array}{l}\text { All sites } \\
(\mathrm{N}=45)\end{array}$ \\
\hline \multicolumn{5}{|l|}{ Median number of staff in facility } \\
\hline Medical staff & 3 & 5 & 4 & 4 \\
\hline Support staff & 2 & 1 & 2 & 1 \\
\hline All staff & 3 & 6 & 5 & 5 \\
\hline \multicolumn{5}{|c|}{ Median number of staff trained on specific aspects } \\
\hline Medical abortion & 2 & 1 & 1 & 1 \\
\hline Comprehensive post-abortion care & 1 & 0 & 1 & 1 \\
\hline VCAT & 0 & 0 & 0 & 0 \\
\hline Family planning & 2 & 1 & 1 & 1 \\
\hline
\end{tabular}




\section{Service Availability}

Eighty per cent of the clinics offered at least one surgical abortion method and a similar proportion offered at least one medical abortion method (Table 5). MVA was the most common surgical abortion method, while Misoprostol alone was the most common medical abortion method available in the clinics. Almost all (91\%) facilities offered either surgical or medical abortion methods, while $69 \%$ offered both methods. Only $11 \%$ of the facilities had Mifepristone alone, while $18 \%$ had a combination of Mifepristone and Misoprostol, reflecting the fact that Mifepristone had just been registered a few months before the study.

More than $90 \%$ of facilities conducted or had conducted at least one procedure related to pre-abortion, pain management, infection prevention or control, and management of complications (Table 5). However, only 33\% of facilities conducted all the procedures related to pre-abortion care, while none had conducted all the procedures related to pain management, infection prevention or control, and management of complications. Virtually all facilities (98\%) reported that they provide family planning information or methods as a separate service. However, only 53\% reported that they provide additional information on when to seek further care and less than half reported providing information on prevention of sexually transmitted infections (STIs) or HIV (49\%), self-care after leaving the health facility (42\%), and resumption of sexual activity (15\%; ).

\begin{tabular}{|c|c|c|c|c|}
\hline Service indicator & $\begin{array}{r}\text { Kisumu } \\
\% \\
(\mathrm{~N}=11)\end{array}$ & $\begin{array}{r}\text { Nairobi } \\
\% \\
(\mathrm{~N}=18)\end{array}$ & $\begin{array}{r}\text { Mombasa } \\
\% \\
(\mathrm{~N}=16)\end{array}$ & $\begin{array}{r}\text { All sites } \\
\% \\
(\mathrm{~N}=45)\end{array}$ \\
\hline \multicolumn{5}{|l|}{ Surgical abortion methods } \\
\hline Manual vacuum aspiration & 54.6 & 72.2 & 87.5 & 73.3 \\
\hline Electric vacuum aspiration & 9.1 & 5.6 & 0.0 & 4.4 \\
\hline Dilatation and evacuation & 27.3 & 22.2 & 0.0 & 15.6 \\
\hline Dilatation and curettage & 27.3 & 27.8 & 6.3 & 20.0 \\
\hline Hysterotomy & 9.1 & 0.0 & 0.0 & 2.2 \\
\hline Any surgical abortion method & 72.7 & 77.8 & 87.5 & 80.0 \\
\hline All surgical abortion methods & 0.0 & 0.0 & 0.0 & 0.0 \\
\hline \multicolumn{5}{|l|}{ Medical abortion methods } \\
\hline Misoprostol (Miso) alone & 81.8 & 50.0 & $93.8^{*}$ & 73.3 \\
\hline Mifepristone (Mife) alone & 0.0 & 5.6 & 25.0 & 11.1 \\
\hline Combination of Mife and Miso & 27.3 & 11.1 & 18.8 & 17.8 \\
\hline Any medical abortion methods & 90.9 & 61.1 & 93.8 & 80.0 \\
\hline \multicolumn{5}{|l|}{ Surgical and/or medical methods } \\
\hline Surgical or medical methods & 90.9 & 83.3 & 100.0 & 91.1 \\
\hline Surgical and medical methods & 72.7 & 55.6 & 81.8 & 68.9 \\
\hline \multicolumn{5}{|l|}{ Pre-abortion processes (4 items) ${ }^{a}$} \\
\hline Any process (at least 1 item) & 100.0 & 94.4 & 87.5 & 93.3 \\
\hline All processes (all 4 items) & 45.5 & 22.2 & 37.5 & 33.3 \\
\hline \multicolumn{5}{|c|}{ Pain management procedures (6 items)a } \\
\hline Any procedure (at least 1 item) & 100.0 & 100.0 & 100.0 & 100.0 \\
\hline All procedures (all 6 items) & 0.0 & 0.0 & 0.0 & 0.0 \\
\hline \multicolumn{5}{|c|}{ Infection prevention and control (6 items) ${ }^{a}$} \\
\hline Any process (at least 1 item) & 100.0 & 83.3 & 100.0 & 93.3 \\
\hline All processes (all 6 items) & 0.0 & 0.0 & 0.0 & 0.0 \\
\hline \multicolumn{5}{|c|}{ Management of complications (8 items)a } \\
\hline Any procedure (at least 1 item) & 100.0 & 94.4 & 93.8 & 95.6 \\
\hline All procedures (all 8 items) & 0.0 & 0.0 & 0.0 & 0.0 \\
\hline \multicolumn{5}{|l|}{ Family planning } \\
\hline Information & 100.0 & 100.0 & 93.8 & 97.8 \\
\hline Methods & 100.0 & 100.0 & 93.8 & 97.8 \\
\hline \multicolumn{5}{|l|}{ Other information services } \\
\hline When to seek further care & 63.6 & 50.0 & 50.0 & 53.3 \\
\hline Prevention of STIs/HIV & 72.7 & 33.3 & 50.0 & 48.9 \\
\hline Self-care after leaving facility & 54.6 & 27.8 & 50.0 & 42.2 \\
\hline Resumption of sexual activity & 36.4 & 5.6 & $6.3^{*}$ & 14.9 \\
\hline $\begin{array}{ll}\text { Notes: } & \text { aSee Table A1 in the Appenc } \\
& \text { sites are statistically signific }\end{array}$ & ms; STIs: S & & & \\
\hline
\end{tabular}




\section{Availability of Drugs, Supplies and Equipment}

Interviewers asked facility in-charges and also requested to see whether various drugs, supplies and equipment for abortion services were available at the facility and in stock on the day of the visit. The clinics had most of the drugs and supplies for surgical abortion ( $81 \%$ of items) as well as for recovery, pain management and treatment of complications (85\% of items; Table 6$)$. However, the proportions of these items that were in stock on the day of interview were lower than what was reported to be available. The clinics also had most of the infrastructural facilities needed to ensure quality care for clients (91\% of items; Table 6$)$. The facilities also had about two-thirds of the equipment for surgical or medical abortion (68\% of items) and services standards and guidelines on abortion (69\% of items). Availability of drugs and supplies for medical abortion at the clinics was very low (15\%) although the proportion of items that were in stock on the day of interview was similar to what was reported to be available (Table 6).

\begin{tabular}{|c|c|c|c|c|}
\hline Indicator & $\begin{array}{r}\text { Kisumu } \\
(\%) \\
(\mathrm{N}=11)\end{array}$ & $\begin{array}{r}\text { Nairobi } \\
(\%) \\
(\mathrm{N}=18)\end{array}$ & $\begin{array}{r}\text { Mombasa } \\
(\%) \\
(\mathrm{N}=16)\end{array}$ & $\begin{array}{r}\text { All sites } \\
(\%) \\
(\mathrm{N}=36)\end{array}$ \\
\hline \multicolumn{5}{|c|}{ Drugs and supplies for surgical abortion (16 items) } \\
\hline Available in facility & 85.2 & 74.3 & 84.4 & 80.6 \\
\hline In stock on day of visit & 81.8 & 72.3 & 55.1 & 68.8 \\
\hline \multicolumn{5}{|c|}{ Drugs and supplies for medical abortion (10 items) } \\
\hline Available in facility & 16.4 & 10.6 & 18.1 & 14.7 \\
\hline In stock on day of visit & 16.4 & 10.6 & 18.1 & 14.7 \\
\hline \multicolumn{5}{|c|}{$\begin{array}{l}\text { Drugs and supplies for recovery, pain management and } \\
\text { complications ( } 6 \text { items) }\end{array}$} \\
\hline Available in facility & 89.4 & 83.3 & 84.4 & 85.2 \\
\hline In stock on day of visit & 78.8 & 79.6 & 78.1 & 78.9 \\
\hline \multicolumn{5}{|c|}{ Equipment for surgical or medical abortion (21 items) } \\
\hline Available in facility & 78.4 & 55.8 & 74.7 & 68.0 \\
\hline In stock on day of visit & 71.8 & 54.0 & 69.6 & 63.9 \\
\hline Service standards and guidelines (5 items) & 74.5 & 58.9 & 76.3 & 68.9 \\
\hline Infrastructure scores (9 items) & 94.9 & 92.0 & 86.1 & 90.6 \\
\hline
\end{tabular}

\section{Provider Knowledge and Attitudes}

Knowledge, attitudes and practices of facility managers are likely to influence the provision of abortion services at health facilities. Facility in-charges were asked about the common legal grounds for procuring induced abortion in the country and whether permission from third parties is required before performing abortion. Providers mostly cited health reasons ( $64 \%$ of providers), preservation of life ( $43 \%$ of providers), and low socio-economic status of clients $(30 \%)$ as the common legal grounds for induced abortion (table 7 ). About a quarter (23\%) of the providers noted that induced abortion can be provided on request, which is contrary to existing laws and regulations. Slightly more than half $(55 \%)$ of the providers reported that permission from third parties (mostly from parents/ guardians or spouses/partners) is needed before performing abortion. About half $(49 \%)$ of providers whose facilities stocked Misoprostol mentioned the correct regimen for pregnancies of various gestational ages (Table 7) while all providers whose clinics stocked the combination of Mifepristone and Misoprostol mentioned the correct regimen (not shown). 


\begin{tabular}{|c|c|c|c|}
\hline Indicator & $\begin{array}{r}\text { Male } \\
(\%)\end{array}$ & $\begin{array}{r}\text { Female } \\
(\%)\end{array}$ & $\begin{array}{r}\text { Both sexes } \\
(\%)\end{array}$ \\
\hline Knowledge of legal grounds for induced abortiona & $(\mathrm{N}=28)$ & $(\mathrm{N}=16)$ & $(\mathrm{N}=44)$ \\
\hline On request & 21.4 & 25.0 & 22.7 \\
\hline Low socioeconomic status & 32.1 & 25.0 & 29.6 \\
\hline Health reasons & 64.3 & 62.5 & 63.6 \\
\hline Rape & 25.0 & 31.3 & 27.3 \\
\hline Incest & 25.0 & 25.0 & 25.0 \\
\hline Preservation of woman's life & 46.4 & 37.5 & 43.2 \\
\hline Third party permissions required for abortion ${ }^{b}$ & $(\mathrm{~N}=28)$ & $(\mathrm{N}=16)$ & $(\mathrm{N}=44)$ \\
\hline No & 42.9 & 37.5 & 40.9 \\
\hline Yes & 53.6 & 56.3 & 54.6 \\
\hline Don't know & 3.6 & 6.3 & 4.6 \\
\hline Persons whose permissions are requireda & $(\mathrm{N}=15)$ & $(\mathrm{N}=9)$ & $(\mathrm{N}=24)$ \\
\hline Parent/guardian & 66.7 & 66.7 & 66.7 \\
\hline Spouse/partner & 66.7 & 77.8 & 70.8 \\
\hline Medical Commissions & 13.3 & 11.1 & 12.5 \\
\hline More than 1 specialist/physician & 20.0 & 0.0 & 12.5 \\
\hline Other & 13.3 & 11.1 & 12.5 \\
\hline $\begin{array}{l}\text { Correctly explained Misoprostol-only regimen for } \\
\text { pregnancies of different gestational ages }\end{array}$ & $\begin{array}{r}55.0 \\
(N=20)\end{array}$ & $\begin{array}{r}38.5 \\
(N=13)\end{array}$ & $\begin{array}{r}48.5 \\
(\mathrm{~N}=33)\end{array}$ \\
\hline
\end{tabular}

\section{Service Provision Practices}

About three-quarters (78\%) of the providers reported that there were instances when their facilities denied abortion clients the services. The most common reasons were because they could not afford to pay (46\%), inappropriate gestational age (34\%), clients' health status was not conducive (20\%), and lack of appropriate equipment (20\%; Figure 5). A significantly higher proportion of male compared to female providers reported inappropriate gestational age as the reason for denying abortion clients the services while a significantly higher proportion of female than male providers reported stock-outs and religious or moral concerns as reasons for denying abortion clients services $(p<0.05$ in each case).

Figure 5: Reasons for denying abortion clients services

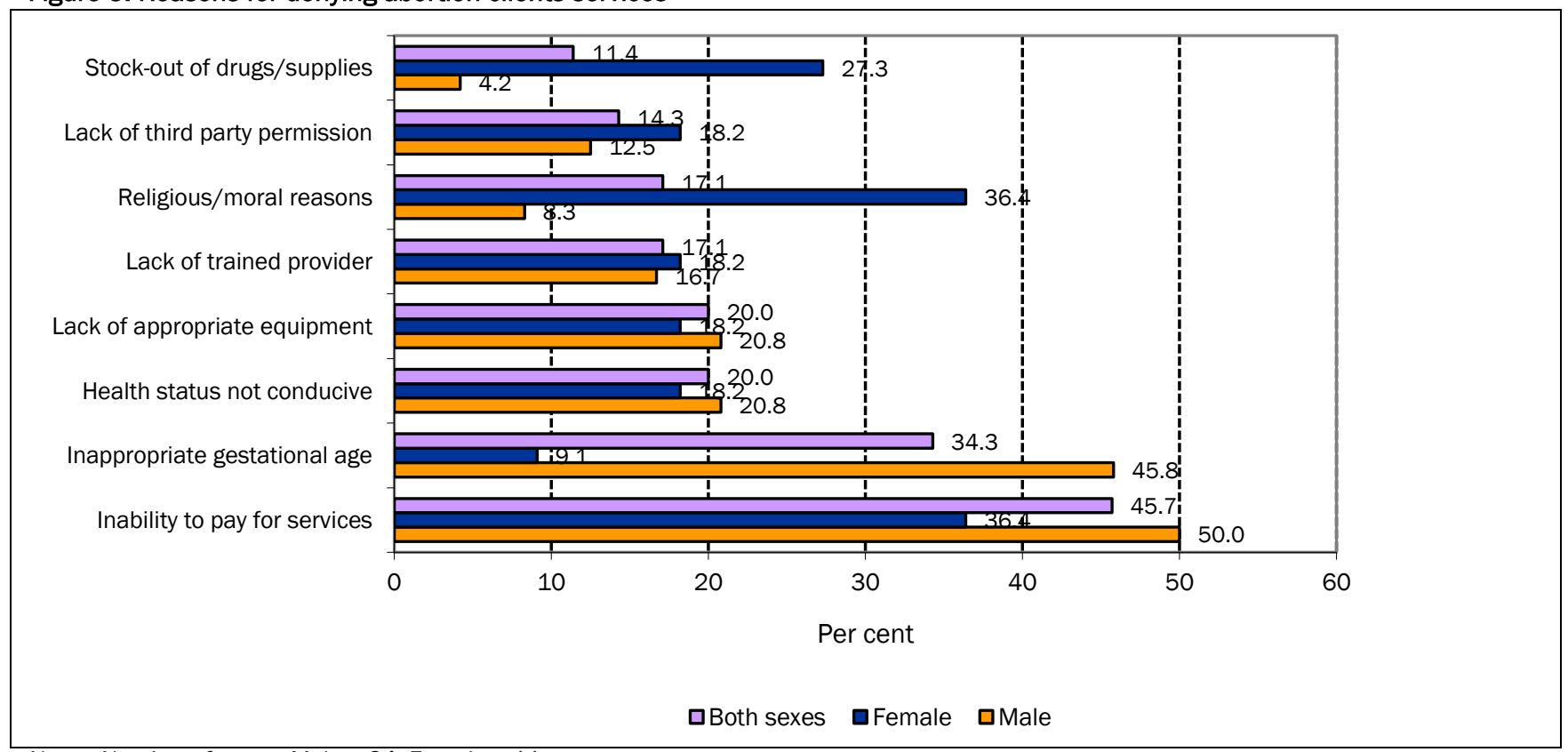

Notes: Number of cases: Males=24; Females=11. 
With respect to observations of client-provider interactions during consultations, the most commonly performed elements were courteous handling of clients ( $74 \%$ of elements performed) and provision of pre-abortion information ( $60 \%$ of elements performed; Table 8 ). The least provided services were providing recommendations following medical examination of clients ( $17 \%$ of elements performed), counselling on family planning ( $40 \%$ of elements performed), and conducting medical examination ( $45 \%$ of elements performed). In all cases, the performance of the elements was highest in Kisumu and lowest in Nairobi (Table 8).

\begin{tabular}{|c|c|c|c|c|}
\hline Indicator & $\begin{array}{r}\text { Kisumu } \\
\% \\
(\mathrm{~N}=62)\end{array}$ & $\begin{array}{r}\text { Nairobi } \\
\% \\
(\mathrm{~N}=58)\end{array}$ & $\begin{array}{r}\text { Mombasa } \\
\% \\
(\mathrm{~N}=21)\end{array}$ & $\begin{array}{r}\text { All sites } \\
\% \\
(\mathrm{~N}=141)\end{array}$ \\
\hline History taking (14 items) & 61.4 & 51.5 & 59.2 & 57.0 \\
\hline Courteous handling of clients (11 items) & 81.4 & 65.3 & 78.8 & 74.4 \\
\hline Provision of pre-abortion information (8 items) & 71.4 & 48.7 & 57.7 & 60.0 \\
\hline Medical examination (15 items) & 49.4 & 40.3 & 43.2 & 44.7 \\
\hline Oral examination (6 items) & 46.8 & 35.9 & 56.3 & 43.7 \\
\hline Physical examination (9 items) & 51.1 & 43.3 & 34.4 & 45.4 \\
\hline Post-examination recommendations (10 items) & 25.5 & 9.1 & 12.4 & 16.8 \\
\hline Post-abortion care counselling (6 items) & 61.3 & 38.5 & 55.6 & 51.1 \\
\hline Counselling on family planning (5 items) & 62.3 & 18.3 & 34.3 & 40.0 \\
\hline Overall quality of care (69 items) & 87.8 & 62.4 & 74.6 & 75.4 \\
\hline
\end{tabular}

Further analysis showed that providers recommended MVA to clients in 57\% of the consultations, Misoprostol alone in 30\% of the consultations, and combination of Mifepristone and Misoprostol in $9 \%$ of the consultations (not shown). Distribution by gestational age showed that providers recommended MVA for $54 \%$ of pregnancies of up to 9 weeks, $59 \%$ of pregnancies above 9 and below 12 weeks, 31\% of pregnancies between 12 and 14 weeks, and 58\% of pregnancies over 14 weeks (not shown). In addition, providers recommended the correct regimen for gestational age in only 31\% of consultations in which medical abortion (Misoprostol alone or combination of Mifepristone and Misoprostol) was recommended. For 43 consultations in which Misoprostol alone was recommended, providers explained the mode of action in $88 \%$ of the cases, and for the 12 consultations where combination of Mifepristone and Misoprostol was recommended, providers explained the mode of action in 11 cases (not shown).

Almost all clients (93\%) were given post-abortion care medication with the highest in Nairobi and lowest in Mombasa (Figure 6). Although $98 \%$ of facilities indicated that they provided family planning information or methods (Table 5), clients were counselled on family planning in $79 \%$ of the consultations and offered family planning methods in only $48 \%$ of consultations, with wide variations between study sites. Few clients were referred to another facility for further help (13\% of consultations).

Figure 6: Distribution of consultations by provision of specific abortion-related services

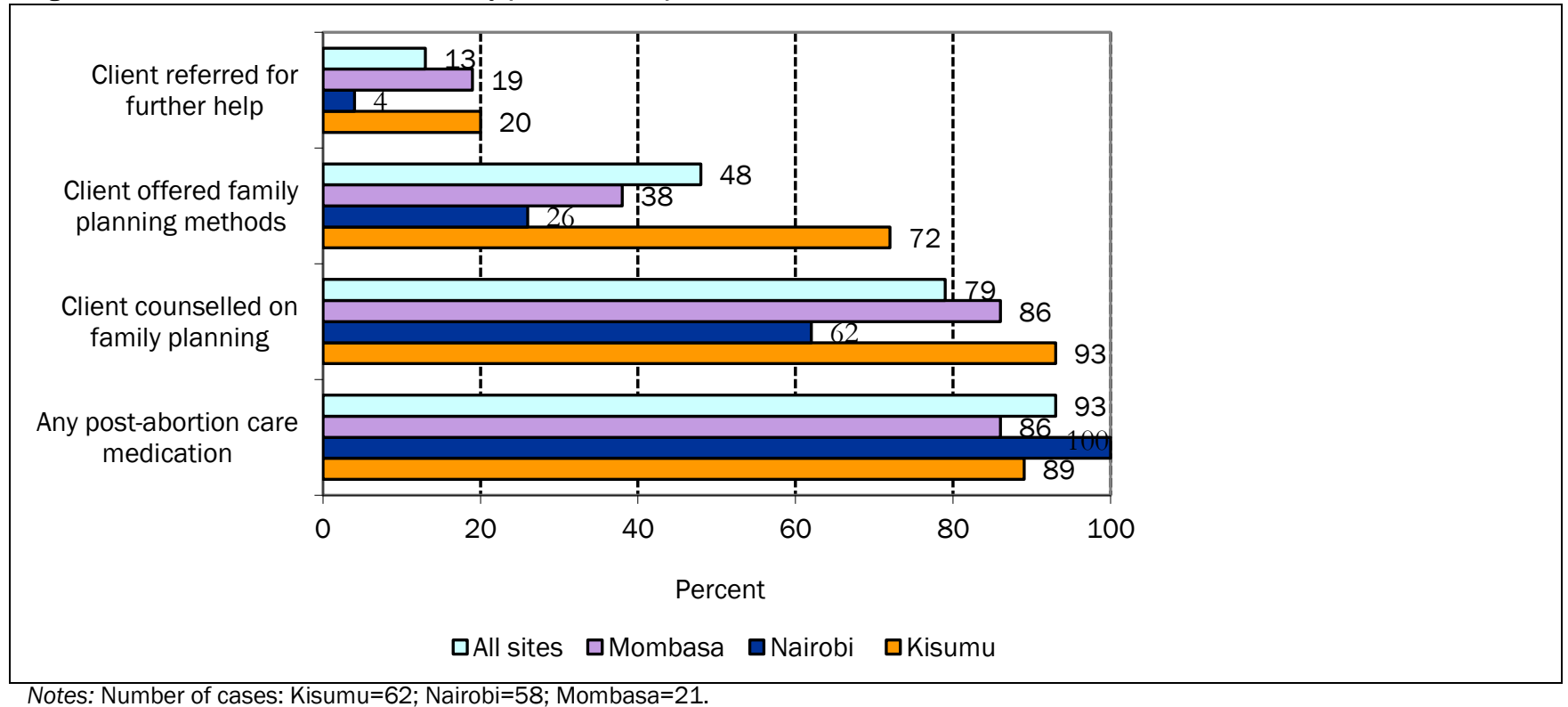

Notes: Number of cases: Kisumu=62; Nairobi=58; Mombasa=21. 


\section{Characteristics of Clients Seeking Abortion Services}

The majority of clients who were observed during consultation and interviewed upon exit were aged between 20 and 29 years (66\%; Table 9). Whereas more than half of the clients in Kisumu (54\%) and Mombasa (52\%) had primary level education or lower, the majority in Nairobi (64\%) had college-level education. Nearly three-quarters (73\%) of the clients in Kisumu were from the two poorest wealth quintiles, $57 \%$ of clients in Nairobi were from the two richest wealth quintiles, and a similar proportion of clients in Mombasa were from the middle and richer quintiles. Many clients (59\%) were never married although there were significant differences between study sites, with the majority of clients in Mombasa (43\%) being formerly married (separated, divorced or widowed). More than half (56\%) of the clients had been pregnant more than once (Table 6) while 54\% had not given birth. Among those who had given birth, 53\% had two or more living children. Sixty per cent of the clients had intention to have children in future while the majority (78\%) desired fewer than 5 children.

\begin{tabular}{|c|c|c|c|c|}
\hline Characteristics & $\begin{array}{r}\text { Kisumu } \\
\% \\
(\mathrm{~N}=48)\end{array}$ & $\begin{array}{r}\begin{array}{r}\text { Nairobi } \\
\% \\
(\mathrm{~N}=56)\end{array}\end{array}$ & $\begin{array}{r}\text { Mombasa } \\
\% \\
(\mathrm{~N}=21)\end{array}$ & $\begin{array}{r}\text { All sites } \\
\% \\
(\mathrm{~N}=125)\end{array}$ \\
\hline Age group & $p=0.86$ & & & \\
\hline$<20$ years & 16.7 & 10.7 & 19.1 & 14.4 \\
\hline $20-29$ years & 62.5 & 69.6 & 61.9 & 65.6 \\
\hline 30 years and above & 20.8 & 19.6 & 19.1 & 20.0 \\
\hline Highest education level & $p<0.01$ & & & \\
\hline Primary or lower & 54.2 & 14.3 & 52.4 & 36.0 \\
\hline Secondary & 33.3 & 21.4 & 42.9 & 29.6 \\
\hline College/university & 12.5 & 64.3 & 4.8 & 34.4 \\
\hline Marital status & $p<0.01$ & & & \\
\hline Never married & 60.4 & 66.1 & 38.1 & 59.2 \\
\hline Married/living together & 29.2 & 28.6 & 19.1 & 27.2 \\
\hline Formerly marrieda & 10.4 & 5.4 & 42.9 & 13.6 \\
\hline Religious affiliation & $p<0.01$ & & & \\
\hline Catholic & 35.4 & 32.1 & 9.5 & 29.6 \\
\hline Protestant/other Christian & 64.6 & 57.1 & 61.9 & 60.8 \\
\hline Muslim/no religion & 0.0 & 10.7 & 28.6 & 9.6 \\
\hline Household wealth index & $p<0.01$ & & & \\
\hline Poorest quintile & 39.6 & 5.4 & 19.1 & 20.8 \\
\hline Poorer quintile & 33.3 & 10.7 & 19.1 & 20.8 \\
\hline Middle quintile & 14.6 & 26.8 & 23.8 & 21.6 \\
\hline Richer quintile & 8.3 & 26.8 & 33.3 & 21.6 \\
\hline Richest quintile & 4.2 & 30.4 & 4.8 & 15.2 \\
\hline Number of times pregnant & $p=0.83$ & & & \\
\hline Once & 45.8 & 44.6 & 38.1 & 44.0 \\
\hline More than once & 54.2 & 55.4 & 61.9 & 56.0 \\
\hline Children ever born & $p=0.59$ & & & \\
\hline 0 & 54.2 & 55.4 & 47.6 & 53.6 \\
\hline 1 & 16.7 & 19.6 & 33.3 & 20.8 \\
\hline 2 and above & 29.2 & 25.0 & 19.1 & 25.6 \\
\hline Number of living children ${ }^{b}$ & $p=0.53$ & & & \\
\hline 0 & 4.8 & 8.0 & 0.0 & 5.3 \\
\hline 1 & 38.1 & 36.0 & 63.6 & 42.1 \\
\hline 2 and above & 57.a & 56.0 & 36.4 & 52.6 \\
\hline Intention to have children in future & $p=0.09$ & & & \\
\hline No & 25.0 & 28.6 & 14.3 & 24.8 \\
\hline Yes & 66.7 & 48.2 & 76.2 & 60.0 \\
\hline Don't know/up to God & 8.3 & 23.2 & 9.5 & 15.2 \\
\hline Number of desired children & $p<0.01$ & & & \\
\hline $1-2$ & 47.9 & 30.4 & 19.1 & 35.2 \\
\hline $3-4$ & 45.8 & 32.1 & 61.9 & 42.4 \\
\hline 5 and above & 4.2 & 3.6 & 14.3 & 5.6 \\
\hline Don't know/up to God & 2.1 & 33.9 & 4.8 & 16.8 \\
\hline $\begin{array}{ll}\text { Notes: } & \begin{array}{l}\text { aSeparated/divorced/widowe } \\
\text { between study sites. }\end{array}\end{array}$ & who had ever give & lues are & quare tes & nces \\
\hline
\end{tabular}




\section{Clients' Experiences and Need for Abortion Services}

Clients who had been pregnant more than once were asked about their previous experiences with miscarriages, still births and abortions. Twenty per cent of them reported having a previous miscarriage or still birth with a significantly lower proportion of clients in Kisumu (4\%) compared to those in Nairobi (26\%) and Mombasa (39\%) reporting such experiences (Table 10). The majority (86\%) who had more than one pregnancy reported having a previous abortion, with significant differences between study sites.

During consultations, observers noted whether the provider asked clients the reasons for wanting to terminate the pregnancy, and if so, the explanations that clients gave. Providers asked for such reasons in $83 \%$ of the consultations. The most commonly given reasons were that the pregnancy was unplanned (73\%), the need to continue with education (24\%), family pressure (14\%), and the need to continue with employment (14\%; Table 10). Interestingly, only two percent of pregnancies were a result of family planning method failure (not shown).

Observers further noted whether the provider established and recorded the gestational age of the pregnancy. Providers established the gestational age of the pregnancy in 90\% of the consultations with more than half (59\%) of clients seeking abortion services at 9 weeks and below while $10 \%$ sought services at more than 14 weeks of pregnancy (Table 10).

\begin{tabular}{|c|c|c|c|c|}
\hline Indicator & $\begin{array}{r}\text { Kisumu } \\
(\%)\end{array}$ & $\begin{array}{r}\text { Nairobi } \\
(\%)\end{array}$ & $\begin{array}{r}\text { Mombasa } \\
(\%)\end{array}$ & $\begin{array}{r}\text { All sites } \\
(\%)\end{array}$ \\
\hline Any previous miscarriages or still births ${ }^{a}$ & $(\mathrm{~N}=26)$ & $(\mathrm{N}=31)$ & $(\mathrm{N}=13)^{*}$ & $(\mathrm{~N}=70)$ \\
\hline No & 96.2 & 74.2 & 61.5 & 80.0 \\
\hline Yes & 3.9 & 25.8 & 38.5 & 20.0 \\
\hline Number of previous abortions ${ }^{a}$ & $(\mathrm{~N}=26)$ & $(\mathrm{N}=31)$ & $(\mathrm{N}=13) * *$ & $(\mathrm{~N}=70)$ \\
\hline 0 & 34.6 & 3.2 & 0.0 & 14.3 \\
\hline 1 & 53.9 & 61.3 & 76.9 & 61.4 \\
\hline 2 or more & 11.5 & 35.5 & 23.1 & 24.3 \\
\hline Reasons for seeking services ${ }^{b}$ & $(\mathrm{~N}=53)$ & $(\mathrm{N}=46)$ & $(\mathrm{N}=17)$ & $(\mathrm{N}=116)$ \\
\hline Education/school & 37.7 & 10.9 & $17.7 * *$ & 24.1 \\
\hline Health reasons & 13.2 & 10.9 & 0.0 & 10.3 \\
\hline Family pressure & 26.4 & 2.2 & $5.9 * *$ & 13.8 \\
\hline Employment-related & 13.2 & 13.0 & 17.7 & 13.8 \\
\hline Unplanned/not ready for child & 64.2 & 82.6 & 76.5 & 73.3 \\
\hline Gestational age at time of seeking carec & $(\mathrm{N}=49)$ & $(\mathrm{N}=58)$ & $(\mathrm{N}=19)^{*}$ & $(\mathrm{~N}=126)$ \\
\hline 9 weeks and below & 53.1 & 69.0 & 42.1 & 58.7 \\
\hline Above 9 and below 12 weeks & 22.5 & 22.4 & 15.8 & 21.4 \\
\hline Between 12-14 weeks & 14.3 & 5.2 & 15.8 & 10.3 \\
\hline Over 14 weeks & 10.2 & 3.5 & 26.3 & 9.5 \\
\hline \multicolumn{5}{|c|}{$\begin{array}{ll}\text { Notes: } & { }^{a} \text { Among those with two or more pregnancies; }{ }^{\circ} \text { Based on observations of client-provider interactions for consultations where } \\
& \text { the provider asked for reasons for wanting to terminate pregnancy; 'Based on observations of client-provider interactions } \\
& \text { for consultations where the provider determined the gestational age of pregnancy; Differences between study sites are } \\
\text { statistically significant at: } * \mathrm{p}<0.05 ; * * p<0.01 \text {. }\end{array}$} \\
\hline
\end{tabular}

\section{Clients' Knowledge and Use of Family Planning}

Clients seeking abortion services were asked about their knowledge and prior use of family planning methods. Ninety eight per cent of the clients reported knowing a family planning method with no significant differences between study sites. The majority (78\%) reported having ever used a family planning method with no significant differences between study sites. The most common methods clients had ever used were male condom, oral pills, injectables, and emergency pill (Figure 7). 
Figure 7: Per cent distribution of clients who had ever used a family planning method by type of method

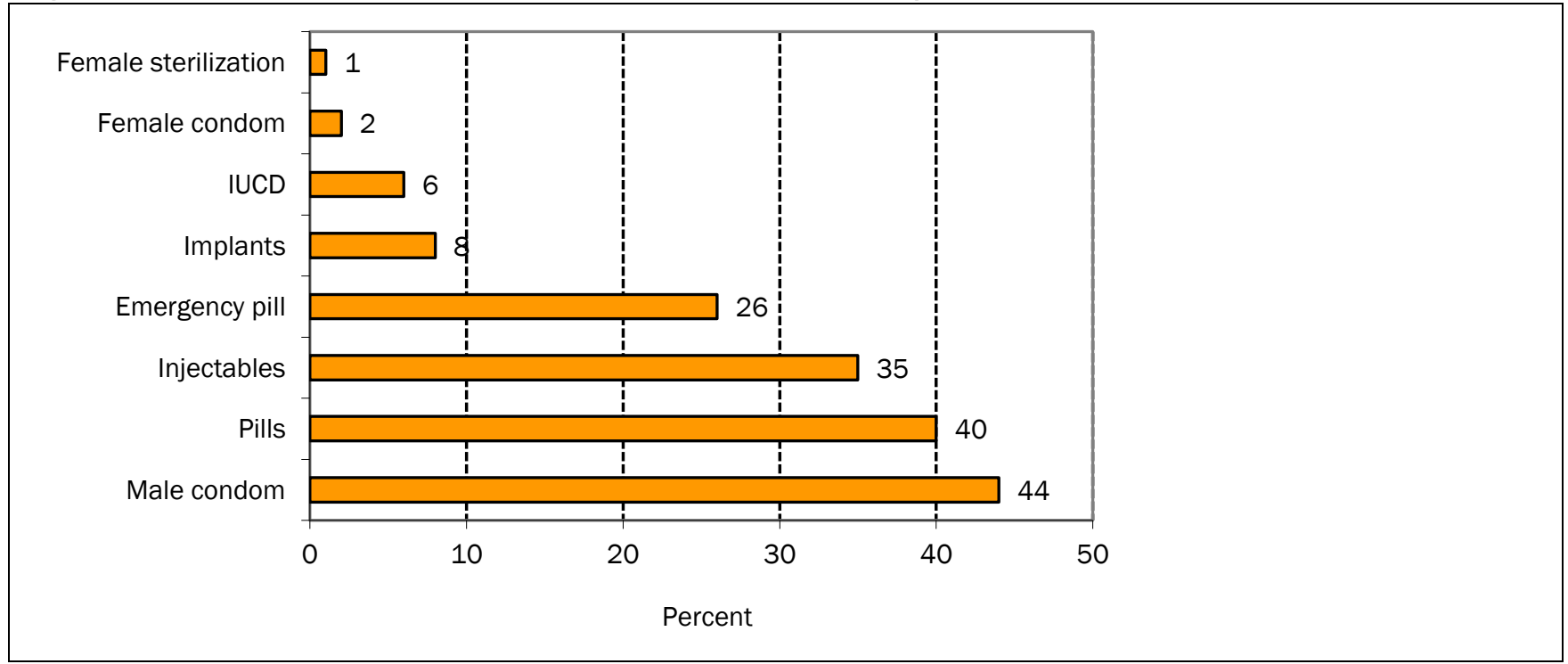

Notes: IUCD: Intra-uterine contraceptive device; Number of cases=97.

Eighty percent of the clients who had ever used family planning obtained a method themselves or together with their partners the last time, while $19 \%$ reported that their partners obtained the method. Among clients who obtained a method by themselves or together with their partners, 36\% got it from private pharmacies, 35\% from private health facilities, and $22 \%$ from public health facilities (Figure 8 ).

Figure 8: Distribution of clients by source of family planning method

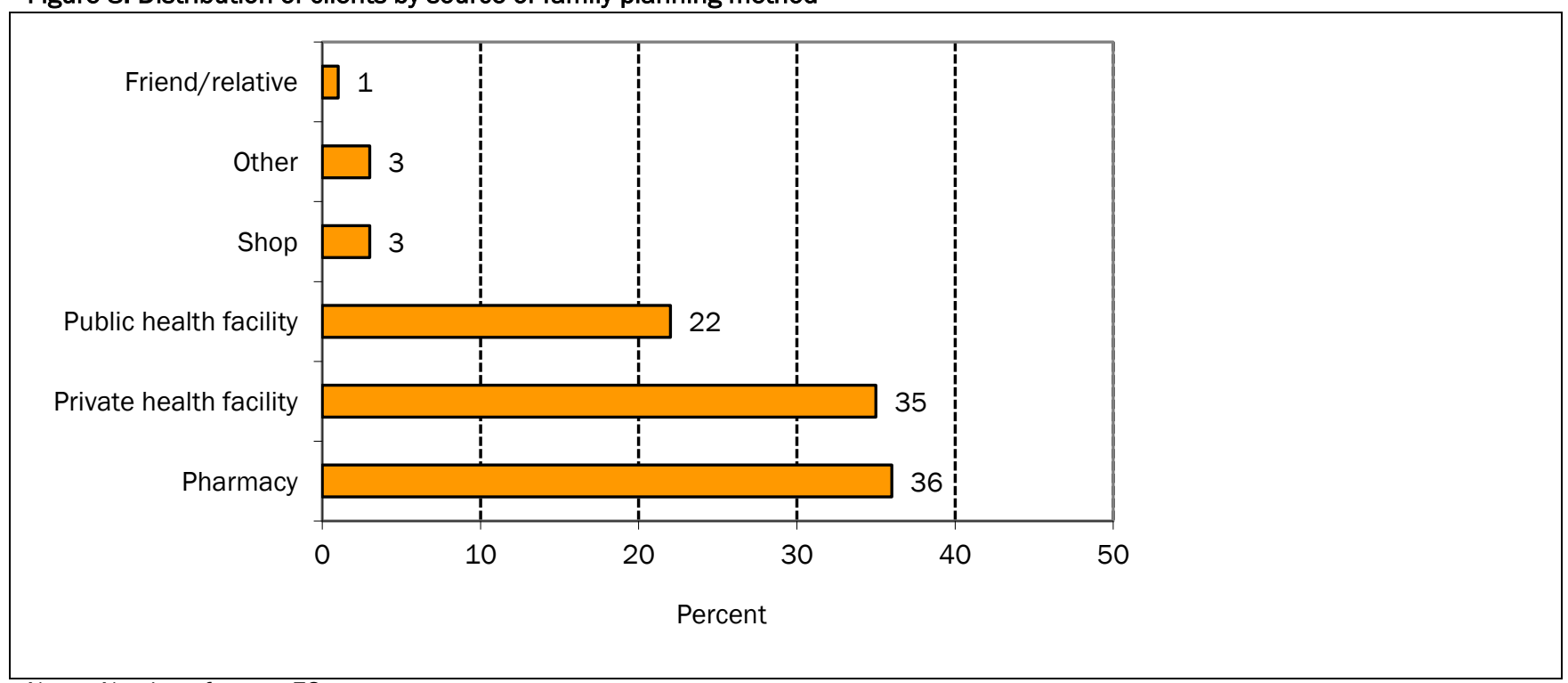

Notes: Number of cases $=78$.

Upon exit, clients were asked whether they decided to use a family planning method and if so, which method. Nearly two-thirds (63\%) chose a family planning method, most commonly injectables (40\%), male condoms (33\%), pills (20\%), implants (18\%), and IUCDs (18\%). Eleven per cent of these clients had not previously used family planning while among those who had previously used a method, $60 \%$ chose a different method. Figure 9 shows a dramatic decline in the use of oral pills and increases in the use of injectables, IUCD and implants among clients who had previously used a method. 
Figure 9: Distribution of clients by type of family planning method ever used and method accepted among those who accepted a different method from that previously used

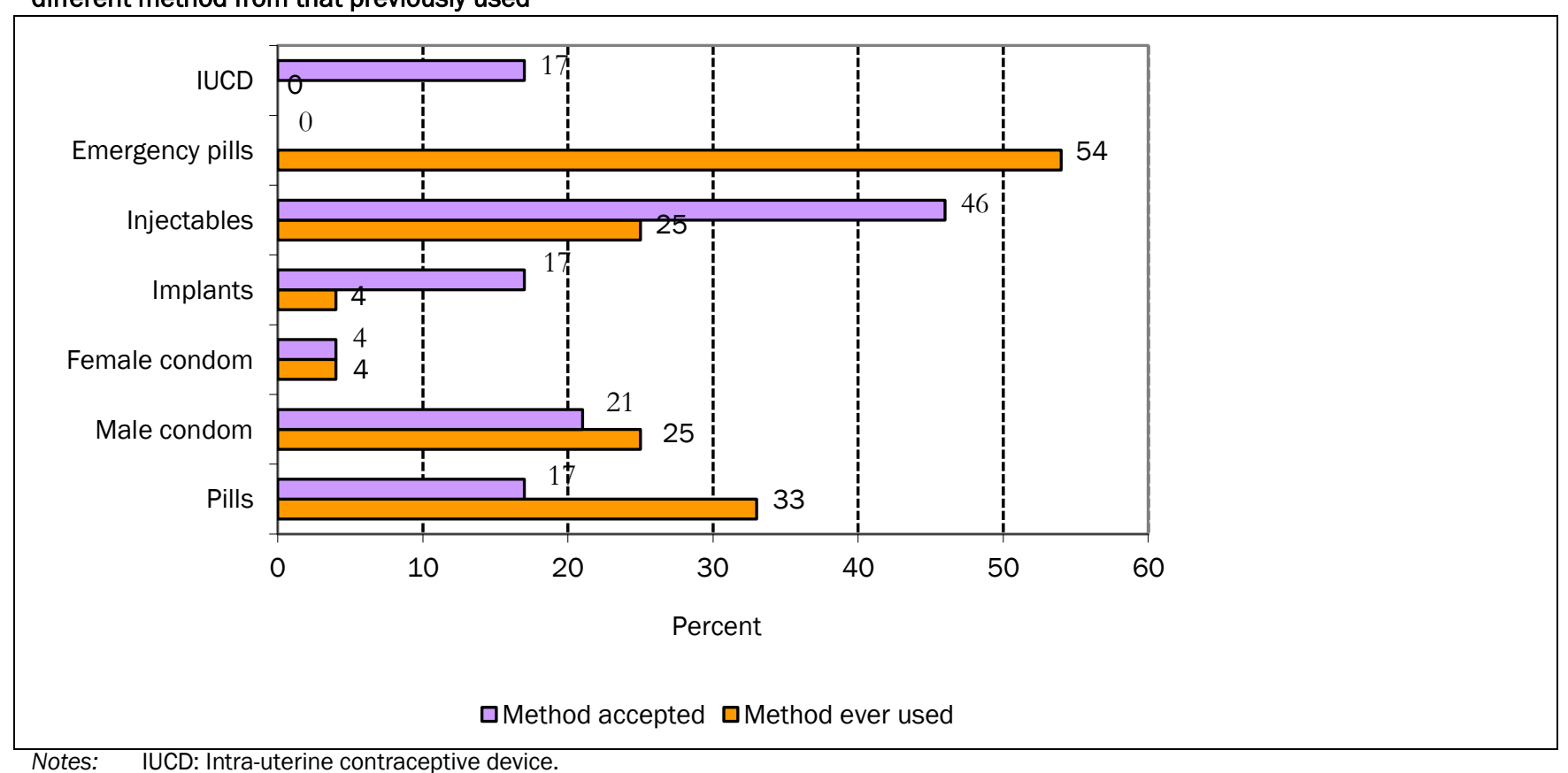

Notes: IUCD: Intra-uterine contraceptive device.

\section{Clients' Perceptions of Services Received}

In all study sites, clients highly rated the consultation process with $96 \%$ of the elements reported as having been performed by the providers (Figure 10). By contrast, providing information on the services being given was the least rated component of the interactions with clients reporting only $58 \%$ of the elements being performed by the providers. Overall ratings of the consultation process and information provided were highest in Kisumu and lowest in Nairobi while rating for history taking and medical examination was highest in Kisumu and lowest in Mombasa (Figure 10).

Figure 10: Indicators of client perceptions about services received

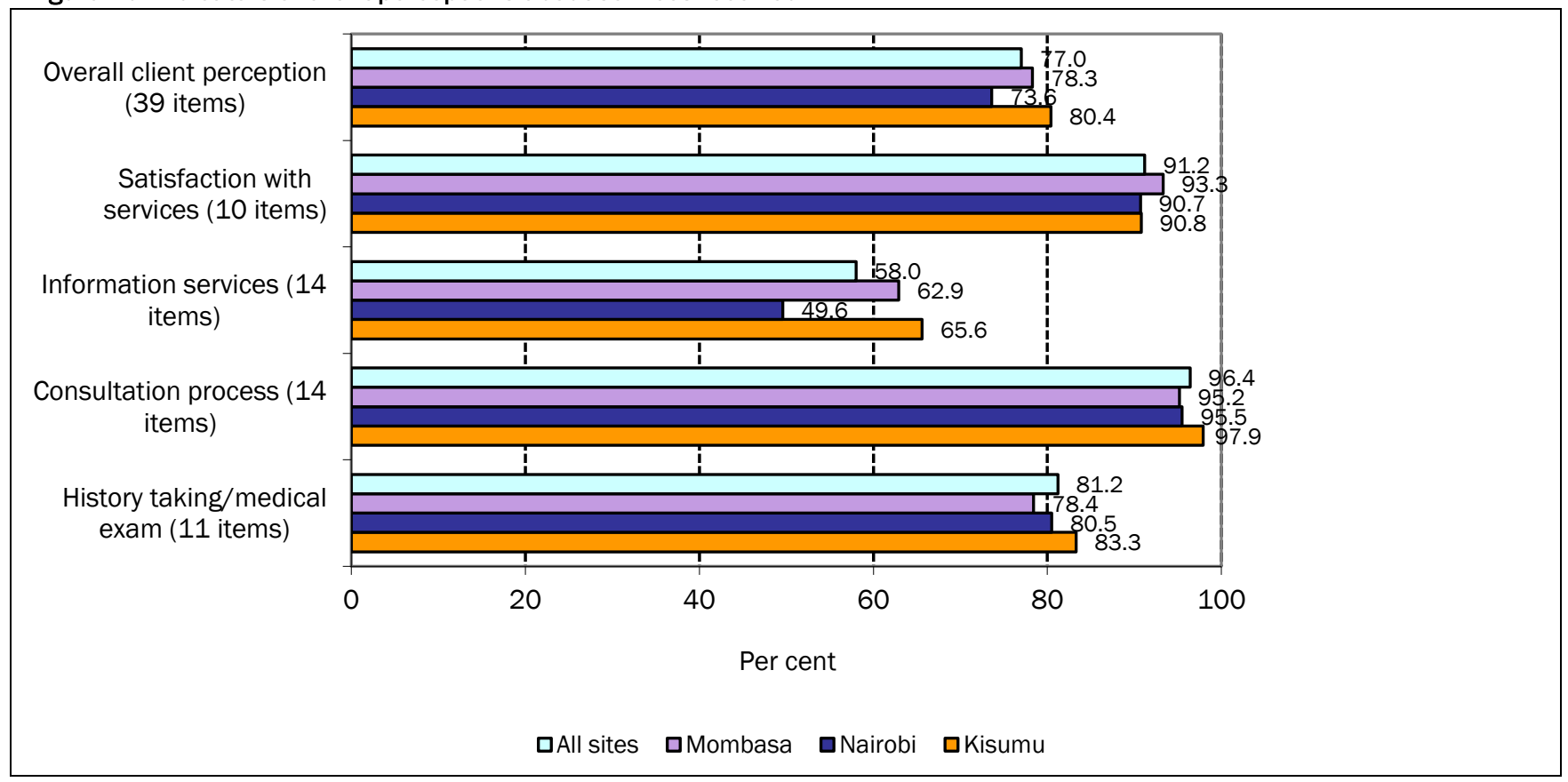


Clients were asked upon exit how long they waited before being seen by the provider from the time they arrived at the facility, and whether they felt that it was reasonable. Most clients $(88 \%)$ reported that the waiting time was reasonable with no significant differences between study sites. The average waiting time was 13 minutes ( 9 minutes in Kisumu, 16 minutes in Nairobi, and 17 minutes in Mombasa). Most (45\%) clients waited between 10 and 29 minutes (Figure 11) with wide variations between study sites.

Figure 11: Per cent distribution of clients interviewed upon exit by waiting time before being seen by the provider

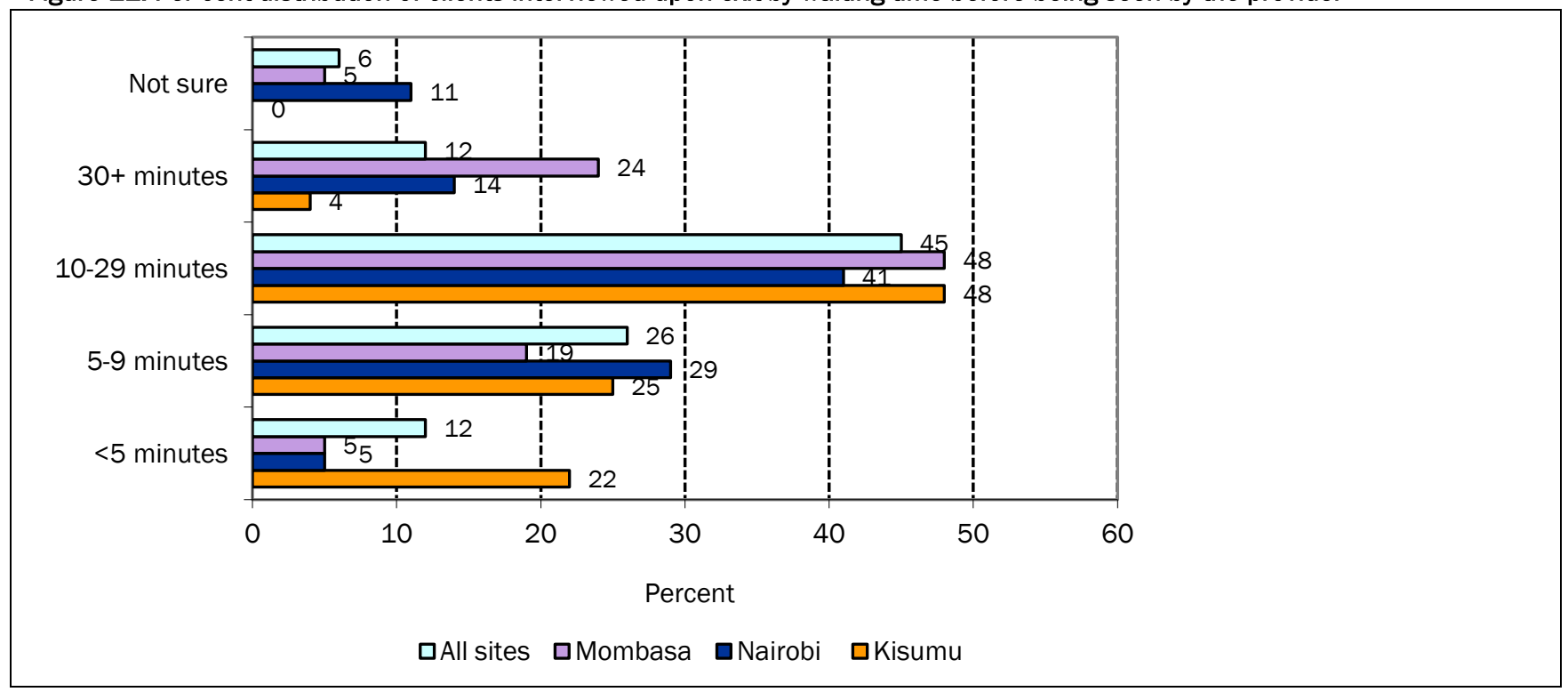

\section{Prices of Abortion Services}

Facility in-charges were asked about the prices of surgical and medical abortion services available at the clinics. The median cost of MVA was KSh. 3,000 ( $\approx$ US $\$ 35$ ) while that of dilatation and evacuation or dilatation and curettage was KSh. 5,000 ( $\approx$ US \$58; Table 11). The median price of the Misoprostol only regimen increased with higher gestation age of pregnancy while the median price for the combination of Mifepristone and Misoprostol for pregnancies of up to 9 weeks was KSh. 5,000 ( $\approx$ US $\$ 58)$. There were wide variations in the prices facilities charge for the methods (Table 11). One provider reported the price of KSh. 5,000 ( $\sim U S \$ 58)$ for combination of Mifepristone and Misoprostol for pregnancies of gestational age of above 9 and below 12 weeks.

Clients were asked upon exit how much they paid for additional elements of abortion service, including transport, consultation card, laboratory tests, other medication, counselling, and family planning methods. The results in Table 11 show that clients' expenses on surgical abortion methods (MVA or dilatation and evacuation were quite high. In addition, consultation fee was, on average, higher than the cost of medication. 


\begin{tabular}{|c|c|c|c|c|}
\hline \multirow[t]{2}{*}{ Services } & $\begin{array}{r}\text { Minimum } \\
(\mathrm{KSH})\end{array}$ & $\begin{array}{r}\text { Maximum } \\
(\mathrm{KSH})\end{array}$ & $\begin{array}{r}\text { Median } \\
(\mathrm{KSH})\end{array}$ & $\begin{array}{r}\text { Number of } \\
\text { clinics }\end{array}$ \\
\hline & \multicolumn{4}{|c|}{ Prices given by clinics } \\
\hline \multicolumn{5}{|l|}{ Cost of surgical abortion methods } \\
\hline Manual vacuum aspiration & 1,500 & 10,500 & 3,000 & 35 \\
\hline Dilatation and evacuation & 3.500 & 15,000 & 5,000 & 7 \\
\hline Dilatation and curettage & 3,500 & 10,000 & 5,000 & 6 \\
\hline \multicolumn{5}{|l|}{ Cost of Misoprostol regimen } \\
\hline 9 weeks and below & 360 & 5,000 & 2,500 & 16 \\
\hline Above 9 and below 12 weeks & 180 & 5,000 & 3,000 & 10 \\
\hline Between 12-14 weeks & 90 & 7,000 & 4,500 & 6 \\
\hline \multicolumn{5}{|l|}{ Cost of combination of Mife and Miso } \\
\hline 9 weeks and below & 1,000 & 7,000 & 5,000 & 5 \\
\hline \multirow[t]{2}{*}{ Above 9 and below 12 weeks $^{a}$} & -- & & -- & 1 \\
\hline & \multicolumn{4}{|c|}{ Expenses incurred by clients } \\
\hline \multicolumn{5}{|l|}{ Client expenses on } \\
\hline Transport & 10 & 800 & 70 & 67 \\
\hline Consultation & 100 & 5,400 & 2,000 & 73 \\
\hline Card & 50 & 8,500 & 50 & 17 \\
\hline Laboratory tests & 99 & 400 & 200 & 25 \\
\hline Medication & 200 & 6,500 & 1,400 & 22 \\
\hline Family planning method(s) & 50 & 3,500 & 100 & 10 \\
\hline Manual vacuum aspiration & 300 & 7,000 & 4,000 & 18 \\
\hline Miso and manual vacuum aspiration & 3,500 & 5,000 & 4,250 & 2 \\
\hline Dilatation and evacuation & 8,000 & 10,000 & 9,000 & 2 \\
\hline \multicolumn{5}{|c|}{ Notes: $\quad$ aOne provider reported KSh. 5,000; KSH: Kenya shilling (1 USD $\approx$ KSH. 85). } \\
\hline
\end{tabular}

\section{SUMMARY AND IMPLICATIONS}

\section{Summary of Findings}

- The most common aspects related to the provision of abortion services that private providers had received inservice training on were infection prevention ( $78 \%$ of facilities), referral procedures ( $76 \%$ of facilities); and managing complications ( $76 \%$ of facilities) while the least aspects were the national standards and guidelines (60\% of facilities) and the legal and policy provisions regarding abortion (51\% of facilities).

- Availability of drugs and supplies for medical abortion was very limited (15\% of items) although the proportion of items that were in stock on the day of interview was similar to what were reported to be available. By contrast, facilities had most of the drugs and supplies for surgical abortion ( $81 \%$ of items) as well as for recovery, pain management and treatment of complications ( $85 \%$ of items) although the proportions of items that were in stock on the day of interview were lower than what was reported to be available.

- Although providers mostly cited health reasons (64\% of providers) and preservation of the mother's life ( $43 \%$ of providers) as the common legal grounds for induced abortion, about a quarter (23\%) noted that induced abortion can be provided on request, which is contrary to existing laws and regulations. In addition, only about half (49\%) of providers whose facilities stocked Misoprostol mentioned the correct regimen for pregnancies of various gestational ages.

- Two-thirds (66\%) of the women seeking abortion services from private clinics were aged between 20 and 29 years, $64 \%$ had at least secondary level education, $59 \%$ were never married while $56 \%$ had a previous pregnancy, with the majority of those who had more than one pregnancy (86\%) reporting having a previous abortion.

- More than half (59\%) of clients seeking abortion services had pregnancies of up to 9 weeks with the most common reason for seeking abortion services being that the pregnancy was unplanned $(73 \%)$ while other reasons included 
the need to continue with education (24\%), family pressure (14\%), and the need to continue with employment (14\%).

- Providers recommended the correct regimen for gestational age in only $31 \%$ of consultations in which medical abortion (Misoprostol alone or combination of Mifepristone and Misoprostol) was offered. By contrast, providers recommended manual vacuum aspiration for $54 \%$ of pregnancies of up to 9 weeks, $59 \%$ of pregnancies above 9 and below 12 weeks, 31\% of pregnancies between 12 and 14 weeks, and 58\% of pregnancies over 14 weeks.

- Although nearly all (98\%) private clinics reported providing family planning information or methods, only $79 \%$ of the clients seeking abortion services were counselled on family planning while $48 \%$ were given a method. Besides, elements of family planning counselling were some of the least performed functions during consultations (40\% of elements performed) while elements of interpersonal relationships such as courteous handling of clients were some of the most performed by providers ( $74 \%$ of elements performed).

- The majority of clients seeking abortion services (78\%) had previously used a family planning method, mostly male condom, oral pills, injectables, and emergency pill. Nearly two-thirds (63\%) chose a method on the day of visit, mostly injectables (40\%), male condoms (33\%), pills (20\%), implants (18\%), and IUCDs (18\%) while $60 \%$ of those who had a previously used a method chose a different method, mostly injectables, IUCD and implants.

- Prices of medical abortion drugs increased with higher gestation age of pregnancy although there were wide variations in the prices facilities charge for the methods, ranging from KSh. 90 ( $\approx U S \$ 1$ ) to KSh. 7,000 ( $U$ US $\$ 82$ ). Prices of surgical abortion methods also varied widely between facilities from KSh. 1,500 ( $\approx \mathrm{US} \$ 18)$ to KSh. $15,000(\approx \mathrm{US} \$ 176)$.

\section{Implications}

- There is need for widespread dissemination of the existing policies and guidelines regarding abortion among private providers to ensure that they offer services within existing regulations.

- There is need to improve the supply chain for medical abortion drugs (especially combined Mifepristone and Misoprostol) in private clinics.

- There is need strategies to improve the capacity of private providers to offer appropriate family planning services to clients seeking abortion, especially long-term methods given the high rate of repeat abortions. 


\section{Study Limitations}

One of the limitations of the study stems from the technique of observing clients and providers during consultations as it is likely that providers may bias their behaviour in a positive way. To address this issue, all observers had medical qualifications as this was expected to raise the comfort levels of the providers such that their behaviours become normative. In addition, it was emphasized during training that at the beginning of the observation the observers should let the providers know that they were not there to evaluate them and that the observers were not experts who could be consulted during the session.

A second limitation was that although facilities were randomly sampled from among those that were members of RHN or the AMUA Franchise, the clients were not randomly sampled as they were observed or interviewed upon exit based on their expressed willingness to participate voluntarily in the study. It could be that those who accepted to participate in the study were self-selecting based on a greater willingness to share their experiences regarding this stigmatized behaviour and so their experiences may not be representative of all clients seeking abortion services from private health facilities.

Another limitation stems from the unclear or ambiguous nature of the Kenyan legal status on abortion, which could have induced study participants, especially private pharmacy workers, to deny knowledge of the subject or to provide responses in line with the prevailing legal and socio-cultural context. In addition, given that written informed consent was obtained from the pharmacy proprietor in advance of the simulated client visits, he/she may have instructed employees to change their practice for the period of the study. The simulated client method itself is also prone to certain biases especially the ability of the simulated client to appropriately enact the assigned role and to recall details of the interaction after the event. 


\section{References}

ANMA (African Network for Medical Abortion) Kenya. 2014. Events. Available at: http://anmakenya.or.ke/?page_id=90. Accessed: November 30, 2015.

Brookman-Amissah, E. and Joyce B. Moyo. 2004. "Abortion law reform in sub-Saharan Africa: no turning back." Reproductive Health Matters 12(24):227-34.

Bruce, J. 1990. "Fundamental elements of the quality of care: a simple framework." Studies in Family Planning 21(2):61-91.

Center for Reproductive Rights. 2010. The impact of Kenya's Restrictive Abortion Law. New York: Center for Reproductive Rights. Accessed at: publications@reprorights.org.

Kenya National Bureau of Statistics (KNBS) and ICF Macro. 2010. Kenya Demographic and Health Survey 20082009. Calverton, Maryland: KNBS and ICF Macro.

Kenya National Bureau of Statistics (KNBS), Ministry of Health (MOH), National AIDS Control Council (NACC), Kenya Medical Research Institute (KEMRI), and National Council for Population and Development (NCPD). 2015. Kenya Demographic and Health Survey 2014: Key Indicators. Nairobi: KNBS, MOH, NACC, KEMRI and NCPD.

KMET (Kisumu Medical and Education Trust). 2014. Programs and Projects. Available at: http://www.kmet.co.ke/. Accessed November 30, 2015.

Levandowski, Brooke A., Erin Pearson, Juliana Lunguzi, and Hans R. Katengeza. 2012. "Reproductive health characteristics of young Malawian women seeking post-abortion care." African Journal of Reproductive Health 16(2):253-261.

Levandowski, Brooke A., Chisale Mhango, Edgar Kuchingale, Juliana Lunguzi, Hans Katengeza, Hailemichael Gebreselassie, and Susheela Sing. 2013. "The incidence of induced abortion in Malawi." International Perspectives on Sexual and Reproductive Health 39(2):88-96.

Ministry of Health [Kenya]. 2003. Kenya National Post Abortion Care Curriculum: Trainer's Manual. Nairobi: Ministry of Health.

Ministry of Health [Kenya]. 2006. Taking the Kenya Essential Package for Health to the Community: A Strategy for the Delivery of Level One Services. Nairobi: Ministry of Health.

Ong'ech, J., J. Osur, M. Makanyengo, M. Mathai, H. Gebreselassie, E. and Brookman-Amissah. 2008. The status of Misoprostol use in Kenya. Nairobi: Ipas Africa Alliance and the National Health and Development Organization (NAHEDO).

PATH (Program for Appropriate Technology in Health). 2004. "Increasing access to reproductive health services through pharmacists” Outlook 21(2). Seattle: PATH.

Reproductive Health Network. 2015. Comprehensive Abortion Care Training Report. Nairobi: Reproductive Health Network.

Republic of Kenya. 2010a. Constitution of Kenya 2010. Nairobi: Republic of Kenya.

Republic of Kenya. 2010b. Sessional Paper on National Pharmaceutical Policy. Nairobi: Republic of Kenya.

Republic of Kenya. 2012. Standards and Guidelines for Reducing Morbidity and Mortality from Unsafe Abortion in Kenya. Nairobi: Republic of Kenya/Ministry of Medical Services.

Republic of Kenya. 2013. Incidence and complications of unsafe abortion in Kenya: Key findings of a national study. Nairobi: African Population and Health Research Center, Ministry of Health, Kenya, Ipas, and Guttmacher Institute.

Sedgh, Gilda, Susheela Singh, and Rubina Hussain. 2014. "Intended and unintended pregnancies worldwide in 2012 and recent trends." Studies in Family Planning 45(3):301-314.

Shah, I. and E. Åhman. 2010. "Unsafe abortion in 2008: global and regional levels and trends." Reproductive Health Matters 18(36): 90-101.

Singh, Susheela, Elena Prada, Florence Mirembe, Charles Kiggundu. 2005. "The incidence of induced abortion in Uganda." International Family Planning Perspectives 31(4):183-191.

Skibiak, J.P., Moyo, M.C., and Ahmed, Y. 2001. Testing alternative channels for providing emergency contraception to young women. Nairobi: Population Council.

United Nations. 1994. International Conference on Population and Development, ICPD. Summary of the Programme of Action. New York: United Nations. Available at: http://www.un.org/ecosocdev/geninfo/populatin/icpd.htm. 
United Nations. 2010. Millennium Development Goal Report 2010; Trends in Maternal Mortality: 1999-2008. New York: United Nations. Available at:

http://www.un.org/millenniumgoals/pdf/MDG\%20Report\%202010\%20En\%20r15\%20low\%20res\%2020100615\%20-.pdf.

Wamugi, S., E. Yegon, T. Fetters, L. Wanaswa, and S. Msipa-Ndebele. 2014. "Women's perceptions about abortion in their communities: perspectives from Western Kenya." Reproductive Health Matters 22(43):149-158.

WHO (World Health Organization). 2004. Unsafe abortion: global and regional estimates of incidence of unsafe abortion and associated mortality in 2000. Geneva: World Health Organization.

WHO (World Health Organization). 2011. Unsafe abortion: global and regional estimates of incidence of unsafe abortion and associated mortality in 2008, $6^{\text {th }}$ edition. Geneva: World Health Organization. 2011. Accessed at http://whqlibdoc.who.int/publications/2011/9789241501118 eng.pdf.

WHO (World Health Organization). 2012. Safe abortion: technical and policy guidance for health systems. Geneva: WHO. 


\section{Appendices}

Table A1: Items used to compute composite scores for indicators of availability of services at facilities

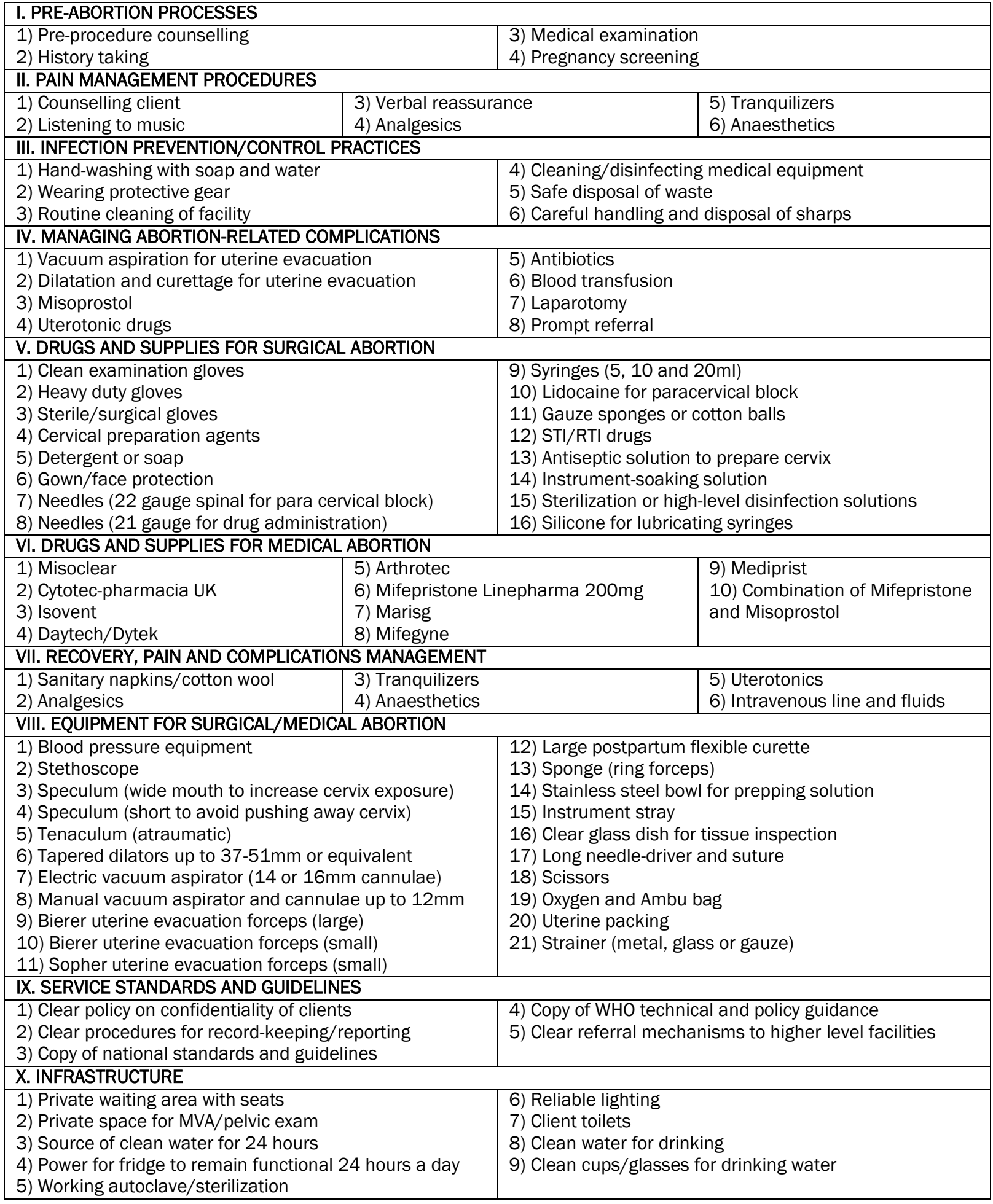


Table A2: Items used to compute composite scores for quality of abortion services

\begin{tabular}{|c|c|c|c|}
\hline \multicolumn{4}{|l|}{ I. HISTORY TAKING } \\
\hline Provider asked: & \multirow{6}{*}{\multicolumn{2}{|c|}{$\begin{array}{l}\text { 6) Previous use of family planning } \\
\text { 7) Client discussed family planning with } \\
\text { partner } \\
\text { 8) Partner cooperation } \\
\text { 9) History of medical conditions } \\
\text { 10) STIs/HIV risk factors }\end{array}$}} & 11) Unprotected sexual intercourse \\
\hline 1) Purpose of visit & & & 12) Gender-based violence \\
\hline 2) Client's age & & & 13) Allergies \\
\hline 3) Client's marital status & & & 14) Reasons for wanting to terminate \\
\hline 4) Number of sexual partners & & & \\
\hline 5) Previous pregnancy history & & & \\
\hline \multicolumn{4}{|l|}{ II. MEDICAL EXAMINATION: ORAL } \\
\hline \multicolumn{2}{|l|}{ Provider discussed: } & \\
\hline \multicolumn{2}{|c|}{ 1) Date of last menstrual period } & \multicolumn{2}{|c|}{ 4) Previous history of ectopic pregnancy/STIs } \\
\hline \multicolumn{2}{|c|}{ 2) Whether menstruation was normal } & \multicolumn{2}{|c|}{ 5) Current use of medications } \\
\hline 3) Whether amenorrheic or using & jectables & \multicolumn{2}{|c|}{ 6) Experiences of violence or coercion } \\
\hline \multicolumn{4}{|c|}{ III. MEDICAL EXAMINATION: PHYSICAL } \\
\hline Provider examined/performed: & \multirow{2}{*}{\multicolumn{2}{|c|}{ 4) Abdomen }} & \\
\hline 1) Pulse & & & 7) Presence of STIs/RTIs \\
\hline 2) Blood pressure & \multicolumn{2}{|c|}{ 5) Softening cervical isthmus } & 8) Mass pelvic examination \\
\hline 3) Temperature & \multicolumn{2}{|c|}{ 6) Softening and enlarging of uterus } & 9) Bimanual examination \\
\hline \multicolumn{4}{|c|}{ IV. POST-EXAMINATION RECOMMENDATIONS } \\
\hline 1) Pregnancy test & \multirow{4}{*}{\multicolumn{2}{|c|}{$\begin{array}{l}\text { 5) Blood test for haemoglobin only } \\
\text { 6) Blood test for full haemogram } \\
\text { 7) Ectopic pregnancy test } \\
\text { 8) Checking for history of STIs/RTIs }\end{array}$}} & 9) Investigating bleeding tendencies in \\
\hline 2) Ultrasound & & & the family \\
\hline 3) Rhesus test & & & 10) Investigating gender-based \\
\hline 4) HIV counselling/testing & & & violence \\
\hline \multicolumn{4}{|c|}{ V. POST-ABORTION CARE COUNSELLING } \\
\hline \multicolumn{4}{|l|}{ Provider counsels client on: } \\
\hline 1) When to seek further care & \multirow{2}{*}{\multicolumn{2}{|c|}{$\begin{array}{l}\text { 3) When to resume sexual activity } \\
\text { 4) Prevention of STIs/HIV }\end{array}$}} & 5) Family planning \\
\hline 2) Self-care after leaving facility & & & 6) Any other post-abortion aspect \\
\hline VI. OVERALL ASSESSMENT OF CC & SULTATION & & \\
\hline 1) Provider observed infection $\mathrm{pr}$ & ention procedures & 5) Provider emp & asised importance of dual protection \\
\hline 2) Provider informed client about & IV/VCT & 6) Provider gave & lient reminder of when to return \\
\hline 3) Provider conducted HIV/STI ris & assessment & 7) Physical infra & tructure ensured client comfort \\
\hline 4) Provider counselled client in a & ipportive way & 8) Physical facili & es ensured audio and visual privacy \\
\hline VII. CLIENT PERCEPTIONS: HISTO & TAKING/MEDICAL EX & IINATION & \\
\hline Provider: & & 6) Asked about & st menstrual period \\
\hline 1) Asked about purpose of visit & & 7) Asked about & uration of pregnancy \\
\hline 2) Asked about medical history & & 8) Checked bloo & pressure \\
\hline 3) Asked about age & & 9) Performed ab & ominal examination \\
\hline 4) Asked about marital status & & 10) Asked abou & fertility experiences and intentions \\
\hline 5) Asked about support from par & & 11) Asked abou & orevious use of family planning \\
\hline VIII. CLIENT PERCEPTIONS: CONS & TATION PROCESS & & \\
\hline Provider: & & & \\
\hline 1) Ensured privacy & & 3) Showed non-j & dgemental attitude \\
\hline 2) Sought consent in a respectfu & Ianner & 4) Talked in a la & guage client understood \\
\hline IX. CLIENT PERCEPTIONS: INFOR & ITION GIVEN & & \\
\hline Provider gave information on: & & & \\
\hline 1) What was going to be done & & 8) Other availab & options for managing the pregnancy \\
\hline 2) What client is likely to experie & & 9) Available psy & o-social support services \\
\hline 3) How long the process would to & & 10) Child-spacin & and family planning \\
\hline 4) Risks and complications asso & ted with the process & 11) STIS/HIV & \\
\hline 5) How to manage pain & & 12) Whether an & when to return to facility \\
\hline 6) What to do in case of complic & & 13) Written mat & ials on services that client received \\
\hline 7) When client is likely to resume & ormal activities & 14) Referral to a & other clinic for more services \\
\hline X. CLIENT PERCEPTIONS: SATISF & TION WITH SERVICES & & \\
\hline 1) Facility is clean/tidy & & 6) Drugs/medic & es are always available at facility \\
\hline 2) Waiting time before seeing prc & der was reasonable & 7) Provider treat & d client with respect \\
\hline 3) Provider is always available at & facility & 8) Confidentialit & privacy was ensured \\
\hline 4) Provider was responsive/unde & anding & 9) Cost of servic & s was reasonable \\
\hline 5) Provider was knowledgeable & & 10) Client was $h$ & ppy overall with services at the facility \\
\hline
\end{tabular}



